\title{
Contrasting the Functional Properties of GABAergic Axon Terminals with Single and Multiple Synapses in the Thalamus
}

\author{
Nicolas Wanaverbecq, ${ }^{1 *}$ Ágnes L. Bodor, ${ }^{2 *}$ Hajnalka Bokor, ${ }^{2}$ Andrea Slézia, ${ }^{2}$ Anita Lüthi, ${ }^{3}$ and László Acsády ${ }^{2}$ \\ ${ }^{1}$ Department of Neurovegetative Physiology, Centre de Recherche de Neurobiologie-Neurophysiologie de Marseille (CRN2M), CNRS-UMR 6231, \\ University of Aix-Marseille II-III, 13397 Marseille Cedex 20, France, ${ }^{2}$ Institute of Experimental Medicine, Hungarian Academy of Sciences, 1083 Budapest, \\ Hungary, ${ }^{3}$ Département de Biologie Cellulaire et de Morphologie, University of Lausanne, 1005 Lausanne, Switzerland
}

\begin{abstract}
Diverse sources of GABAergic inhibition are a major feature of cortical networks, but distinct inhibitory input systems have not been systematically characterized in the thalamus. Here, we contrasted the properties of two independent GABAergic pathways in the posterior thalamic nucleus of rat, one input from the reticular thalamic nucleus (nRT), and one "extrareticular" input from the anterior pretectal nucleus (APT). The vast majority of nRT-thalamic terminals formed single synapses per postsynaptic target and innervated thin distal dendrites of relay cells. In contrast, single APT-thalamic terminals formed synaptic contacts exclusively via multiple, closely spaced synapses on thick relay cell dendrites. Quantal analysis demonstrated that the two inputs displayed comparable quantal amplitudes, release probabilities, and multiple release sites. The morphological and physiological data together indicated multiple, single-site contacts for nRT and multisite contacts for APT axons. The contrasting synaptic arrangements of the two pathways were paralleled by different short-term plasticities. The multisite APT-thalamic pathway showed larger charge transfer during $50-100 \mathrm{~Hz}$ stimulation compared with the nRT pathway and a greater persistent inhibition accruing during stimulation trains. Our results demonstrate that the two inhibitory systems are morpho-functionally distinct and suggest and that multisite GABAergic terminals are tailored for maintained synaptic inhibition even at high presynaptic firing rates. These data explain the efficacy of extrareticular inhibition in timing relay cell activity in sensory and motor thalamic nuclei. Finally, based on the classic nomenclature and the difference between reticular and extrareticular terminals, we define a novel, multisite GABAergic terminal type (F3) in the thalamus.
\end{abstract}

Key words: GABA; axon terminal; basal ganglia; reticular nucleus; synapse; barrel

\section{Introduction}

Many neurons contact their targets via a single synapse (Gulyás et al., 1993; Shepherd and Harris, 1998), but multiple synapses between presynaptic and postsynaptic partners are also abundant in the CNS. A priori, two fundamentally different arrangements of multiple synapses exist. A single axon may innervate its target via multiple terminals, each establishing a single synapse (Buhl et al., 1994; Auger et al., 1998; Tamás et al., 1998) or via terminal(s) forming multiple synapses (Kraushaar and Jonas, 2000; Tel-

Received July 9, 2008; revised Aug. 15, 2008; accepted Sept. 3, 2008.

This work was supported by the Wellcome Trust (L.A. is in receipt of a Wellcome Trust International Senior Research Fellowship and a project Grant 084651), the Hungarian Scientific Research Fund (0TKA 49100, 64184, and 75676), the Institut du Cerveau et de la Moëlle épiniere, the Synapsis Foundation, the Schüller-Stiftung, the Schweizerische Mobiliarversicherungsgesellschaft, the MBF Foundation, an anonymous foundation, and the Swiss National Science Foundation (No. 3100A0_116006). N.W. and A.L. performed the experimental portions of this work at the Biozentrum, University of Basel, Basel, Switzerland. We thank Dr. Balázs Hangya for his help in the statistical analysis, and Krisztina Faddi and Győzző Goda for their excellent technical assistance. We thank Prof. Zoltán Nusser, Dr. Szabolcs Káli, Dr. Lisa Mapelli, and Fabio Longordo for their comments on this manuscript and Prof. Peter Somogyi for providing us the anti-GABA antiserum.

${ }^{*} N . W$. and A.L.B. contributed equally to this work.

Correspondence should be addressed to László Acsády, Institute of Experimental Medicine, Hungarian Academy of Sciences, Szigony u. 43, H-1083 Budapest, Hungary. E-mail: acsady@koki.hu.

D01:10.1523/JNEUROSCI.3183-08.2008

Copyright $\odot 2008$ Society for Neuroscience $\quad$ 0270-6474/08/2811848-14\$15.00/0 gkamp et al., 2004). Whether and how these two arrangements give rise to different functional impact has remained elusive, because synaptic strength depends on a number of ultrastructural and physiological properties. Ideally, two independent inputs should be compared, which converge on the same cell and display comparable quantal parameters, such as number of release sites $(N)$, probability of release $(p)$, and quantal content $(q)$. However, a convergence satisfying all these criteria is rare and has never been described in the case of GABAergic inputs, although both single-site (Auger et al., 1998) and multiple-site terminals (Kraushaar and Jonas, 2000; Telgkamp et al., 2004) exist.

Relay cells of the posterior thalamic nucleus (Po) receive dual GABAergic afferents. One of them arises from the well known reticular thalamic nucleus (nRT) and is responsible for the global modulation of rhythmic thalamocortical activities according to arousal state (Pinault, 2004). The other originates from two extrareticular sources, the zona incerta, and the anterior pretectal nucleus (APT) (Barthó et al., 2002; Bokor et al., 2005). These two nuclei exert powerful control over their postsynaptic partners, gating the response of relay cells to peripheral stimulation (Trageser and Keller, 2004; Bokor et al., 2005; Lavallée et al., 2005). Previous single section electron microscopic analysis indicated that the nRT-thalamic and APT-thalamic inputs may differ in the 
number of synapses a single terminal establishes on its postsynaptic partner (Montero and Scott, 1981; Liu et al., 1995b; Bokor et al., 2005). Thus, the synaptic arrangement of reticular and extrareticular afferents may potentially be suitable to elucidate the role of active zone organization and could help to define the cellular bases underlying the physiological roles of these two GABAergic afferent systems in the thalamus.

In the present study, we tested the functional consequences of combining active zones into one terminal, or keeping them separate, using these two GABAergic inputs converging in the same nucleus of the thalamus. Parallel morphological and physiological examination demonstrated that the two afferents display similar quantal parameters but a strikingly different organization of the synapses, which is reflected in different short-term plasticities of the two pathways. Based on these data, we define a novel terminal type (F3) in the thalamus, according to the nomenclature of the original classifications (Sherman and Guillery, 2006).

\section{Materials and Methods}

All experimental procedures were performed according to the ethical guidelines of the Institute of Experimental Medicine, Hungarian Academy of Sciences and the Veterinary Office of the Canton Basel-Stadt and approved by the respective Ethical Committees.

\section{Anatomy}

\section{Surgery, perfusion}

In deep anesthesia (Equitesin, $0.3 \mathrm{ml} / 100$ g, i.p.), anterograde tracers, biotin-dextran amine (10000 MW; Invitrogen; $10 \%$ in saline), were injected into male Wistar rats [postnatal day 45 (P45)-P60; 250-400 g] via a glass capillary (tip, outer diameter: 5-20 $\mu \mathrm{m}$ ) for 15-30 min (0.5-4.0 $\mu \mathrm{A} ; 2-7 \mathrm{~s}$ on/off duty cycle) according to the atlas of Paxinos and Watson (1998). Coordinates for the nRT were $1.8-1.9 \mathrm{~mm}$ posterior, $2.8 \mathrm{~mm}$ lateral, and $4.7-5.0 \mathrm{~mm}$ ventral to the bregma $(n=16)$ for the APT; $4.8-5.2 \mathrm{~mm}$ posterior, $1.7-2.0 \mathrm{~mm}$ lateral, and $4.5-5.5 \mathrm{~mm}$ ventral to the bregma $(n=10)$. In certain cases, the $\mathrm{nRT}$ was physiologically identified before the tracer injection. After a survival time of $6-8 \mathrm{~d}$, rats were deeply anesthetized with Equitesin (chlornembutal, $0.3 \mathrm{ml} / 100$ g, i.p.), then perfused with a sequential low $\mathrm{pH} /$ high $\mathrm{pH}$ fixative (Berod et al., 1981).

\section{Immunohistochemistry}

For details of the preembedding immunocytochemistry, see Bokor et al. (2005). Briefly, for light microscopic analysis, injection sites and labeled fibers were visualized with nickel-intensified $D A B$ reaction using the $\mathrm{ABC}$ method. For electron microscopic examination, the tracer was visualized with preembedding gold method after tyramide (PerkinElmer Life Sciences) amplification. All sections were treated with $\mathrm{OsO}_{4}(1 \%$ for $45 \mathrm{~min}$ for DAB staining; $1 \% 1 \mathrm{~min}$ and $0.5 \%$ for $20 \mathrm{~min}$ in $4^{\circ} \mathrm{C}$ for immunogold staining in $0.1 \mathrm{~m}$ phosphate buffer), dehydrated in ethanol and propylene oxide, and embedded in Durcupan (ACM; Fluka). During dehydration, the sections were treated with $1 \%$ uranyl acetate in $70 \%$ ethanol for $40 \mathrm{~min}$.

Tissue blocks from Po containing silver intensified gold-labeled terminals from nRT $(n=2)$ or APT $(n=3)$ were reembedded, and 200-300 section long series of $60 \mathrm{~nm}$ thick ultrathin sections were cut with an ultramicrotome. Alternate sections were mounted on copper and nickel grids. Postembedding GABA immunostaining was performed on nickel grids according to the protocol of Somogyi et al. (1985). The specificity of the GABA antibody was extensively characterized by the laboratory of origin (Hodgson et al., 1985).

\section{Three-dimensional reconstruction and measurements}

Serial electron micrographs were taken with Megaview digital camera implanted in a HITACHI 7100 electron microscope. The three-dimensional (3D) reconstructions were made by AnalySIS software (Olympus). The bouton membranes, the synapses, the puncta adhaerentia (PA), and the glial sheathes covering the terminals were reconstructed.

Details of the 3D EM analysis. The membrane of the boutons, the synapses, and glial processes could be identified in more than one ultrathin sections; thus, the outline of these elements was drawn and connected to the outline of the same structure on the next section. Synapses were considered only if the synaptic cleft and the vesicle accumulation were visible on minimally two consecutive $60 \mathrm{~nm}$-thick sections. PA were often visible on only one section, since their sizes are frequently in the range of the section thickness. Thus, the PA outline was drawn on the section where it was visible and then duplicated on the next section in each case to the same direction. These two outlines were connected to each other. Without this process, in many cases, PA would remain twodimensional objects and could not be visible on the 3D images of the whole boutons. We found that this method was the best approximation to obtain the real appearance of these structures as judged from the occasional tangential view of the PA network obtained when the plane of the section was parallel to the bouton surface.

The volume, the surface, the largest diameter of the reconstructed boutons, and the intersynaptic distances were measured using AnalySIS. The distances between two synapses were measured between the two closest points of the reconstructed synapses. Using these data, the nearest neighbor synaptic distances and the number of neighboring synapses within given distances were also determined. The diameter of each postsynaptic or randomly selected profile was measured on three different sections, and their average was calculated. To measure synaptic areas, the lengths of the synapses were determined on each section where a given synapse was visible, summated, and multiplied by the thickness of the sections $(60 \mathrm{~nm})$.

Database of $n R T$ terminals. Seventy-eight anterogradely labeled nRT profiles were eligible for ultrastructural analysis in the Po. Sixty-six of them were conventional axon terminals, of which 41 were followed endto-end, 25 partially reconstructed. In four cases, two closely spaced varicosities were not separated by an obvious, thin intervaricose segment ("double-headed" terminals, end-to-end reconstruction, $n=1$; partial reconstruction, $n=3$ ) (supplemental Movie S3, available at www. jneurosci.org as supplemental material). Four additional labeled elements proved to be intervaricose axon segments with a synapse. Finally, four boutons were discarded from the sample. Two of these displayed markedly different ultrastructural features compared with the other 74 elements, one of them was GABA-negative and in one case the GABA immunoreactivity could not be established. These terminals were regarded as labeling of passing fibers. All of the other 74 profiles included in the analysis were GABA-positive.

Database and ultrastructure of APT terminals. Of the 102 anterogradely labeled elements with sufficient ultrastructural quality, 15 proved to be GABA-negative, confirming a GABA-negative component in the APTthalamic pathway (Bokor et al., 2005; Giber et al., 2008) and were not considered further. Of the 87 GABA-positive profiles followed in serial electron microscopic sections, 83 proved to be axon terminals. Three structures were intervaricose segments. One bouton was discarded from the sample because it displayed markedly different ultrastructural features compared with the other 83 elements. This terminal was regarded as labeling of a passing fiber traversing APT. Thirty-six of the 83 terminals were followed from end-to-end in the serial electron microscopic section, whereas the remaining 47 were partially reconstructed. The exact number and position of the synapses could be unequivocally established in 29 cases.

\section{Statistics}

The diameter distributions of randomly selected dendritic profiles and those contacted by labeled terminals were compared using $\chi^{2}$ test for homogeneity. The correlations between the number of synapses made by a terminal and its volume as well as between the number of synapses formed with a given target and the size of the postsynaptic element were examined using linear regression. The significance of the correlation was determined by one-way ANOVA using Excel. Since most of our data did not show normal distribution, the medians and the interquartile ranges determined by OriginPro 7.5 are shown.

\section{Electrophysiological recordings}

Horizontal slices $(400 \mu \mathrm{m})$, with both the nRT and APT nuclei present and the connections onto ventrobasal nucleus (VB) and Po nuclei pre- 
served, were prepared from brains of 3- to 4-week-old Wistar rats according to standard procedures (Bokor et al., 2005). Slices were transferred one at a time into a recording chamber, perfused at $3.5-4 \mathrm{ml} / \mathrm{min}$ with a solution preheated to $34-35^{\circ} \mathrm{C}$ (in-line solution heater SH-27B; Warner) and containing (in $\mathrm{mm}$ ) $131 \mathrm{NaCl}, 2.5 \mathrm{KCl}, 1.25 \mathrm{NaH}_{2} \mathrm{PO}_{4}, 26$ $\mathrm{NaHCO}_{3}, 2 \mathrm{CaCl}_{2}, 2 \mathrm{MgCl}_{2}, 18$ dextrose, $1.7 \mathrm{~L}(+)$-ascorbic acid, $\mathrm{pH} 7.4$, 315 mOsm. Patch pipettes were filled with a $\mathrm{Cs}^{+}$-based, high $\mathrm{Cl}^{-}$intracellular solution containing (in mM) $120 \mathrm{CsCl}, 10 \mathrm{HEPES}, 8 \mathrm{NaCl}, 0.2$ $\mathrm{MgCl}_{2}$, 2 Mg-ATP, $0.2 \mathrm{Na}-\mathrm{GTP}, 10$ phosphocreatine, 5 QX-314 Br, pH $7.25,290$ mOsm to reduce postsynaptic $\mathrm{Na}^{+}$and $\mathrm{K}^{+}$currents and $\mathrm{GABA}_{\mathrm{B}}$-receptor-mediated currents and to optimize voltage-clamp of thalamic dendrites.

Relay cells in VB and Po were visualized with infrared differential interference contrast microscopy (BX50WI; Olympus) and identified, just after break-through, by prominent rebound burst discharges after injection of hyperpolarizing current $(-150 \mathrm{pA})$. Neurons were voltageclamped at $-60 \mathrm{mV}$ (liquid junction potential $<5 \mathrm{mV}$ not corrected for) and perfused with antagonists for glutamatergic receptors [6,7dinitroquinoxaline-2,3-dione (DNQX), $20 \mu \mathrm{M}]$ and D,L-2-amino-5phosphonovaleric acid (D,L-APV, $50 \mu \mathrm{M})$ to block fast excitatory transmission and to isolate inward currents evoked after activation of $\mathrm{GABA}_{\mathrm{A}}$ receptors. Data were recorded with an Axopatch 200B amplifier (Molecular Devices) in V-Clamp mode, filtered at $2 \mathrm{kHz}$, and digitized at $10-50$ $\mathrm{kHz}$. Series resistances and holding current ranged from 5 to $15 \mathrm{M} \Omega$ and from -20 to $-100 \mathrm{pA}$, respectively. These two parameters were monitored for stability during recordings, and cells were rejected for increases in series resistance $>20 \%$ and for a holding current less than $-100 \mathrm{pA}$. Drugs and solutions with altered ionic composition were bath applied for $5 \mathrm{~min}$ before starting the recordings to ensure full exchange and equilibrium.

\section{Spontaneous events}

Spontaneous IPSCs (sIPSCs) and miniature (mIPSCs) were recorded over a 10 min period in $\mathrm{VB}$ and Po neurons in the absence and presence of $0.5 \mu \mathrm{M}$ TTX, respectively. Spontaneous IPSCs were identified within a 5 min period of recording using template-guided event detection in Clampfit v.9.2. Selected events were aligned and decay time determined by monoexponential fitting. At least 137 events per cell were included (range, 137-533), of which 28-525 were used for monoexponential fitting. Analysis of mIPSCs was carried off-line with automatic detection in MiniAnalysis 6.0.3 (Synaptosoft) with a detection threshold set at $10 \mathrm{pA}$. Subsequently, detected events were visually verified for a $10-90 \%$ rise time smaller than $2 \mathrm{~ms}$. From these scored events, 500 were randomly selected for statistical comparison. When these detection parameters were applied to traces recorded in bicuculline (see Fig. 5A1, inset), no events could be detected (data not shown). sIPSC and mIPSC amplitudes are given in absolute values in the text.

\section{Evoked events}

IPSCs were evoked with $100 \mu$ s current pulses in Po neurons by stimulating either the nRT or the APT, using bipolar tungsten electrodes (spacing, $115 \mu \mathrm{m}$; FHC) or double-barrelled glass electrodes (WPI) filled with bath solution. Such stimuli elicited IPSCs with all-or-none response characteristics (supplemental Fig. S2, available at www. jneurosci.org as supplemental material) and a fixed latency $[2.1 \pm 0.2 \mathrm{~ms}$ and $2.4 \pm 0.3 \mathrm{~ms}$ with coefficient of variation $(\mathrm{CV}=\mathrm{SD} /$ mean $)=0.1 \pm$ 0.02 and $0.07 \pm 0.01$ for $\mathrm{nRT}(n=5)$ and APT $(n=7)$, respectively (supplemental Fig. S2, available at www.jneurosci.org as supplemental material)]. The electrodes were inserted in the most rostral portions of the $\mathrm{nRT}$ or on the borders of the APT and repositioned until a unitary response could be evoked. In a limited series of experiments, slices were prepared from rats injected with anterograde tracers to verify optimal electrode positioning (Bokor et al., 2005). When a connection was found, inhibitory synaptic currents elicited in both nRT (nRT-IPSCs) or APT (APT-IPSCs) showed a sharp threshold for stimulation intensities $\sim 100$ $\mu \mathrm{A}$ that varied little from one experiment to the next (supplemental Fig. S2, available at www.jneurosci.org as supplemental material). For baseline responses and for collection of time-stable series of events in multiple probability fluctuation analysis (MPFA), IPSCs were elicited at 0.2
Hz. To change release probabilities, the $\mathrm{Ca}^{2+} / \mathrm{Mg}^{2+}$ concentrations were altered between (in $\mathrm{mm} / \mathrm{mm}$ ) $0.5 / 4,1 / 3,2 / 2,4 / 0.5$, and $8 / 0.5$, yielding $\mathrm{Ca}^{2+} / \mathrm{Mg}^{2+}$ ratios of $0.125,0.333,1,8$, and 16 . Concentrations were chosen such that the total divalent cation concentration remained at least $4 \mathrm{~mm}$. The effects of bicarbonate buffering on divalent cation concentrations were not taken into account (Schneggenburger et al., 1999).

IPSC amplitudes were measured as the peak of the current evoked by the stimulation from which the holding current preceding the stimulation artifact was subtracted and are given in absolute values in the Results. To assess short-term plasticity of APT- and nRT-IPSCs, highfrequency trains of stimuli $(10,50$, and $100 \mathrm{~Hz})$ were applied. Typically, 10 pulses repeated 10 times at $15 \mathrm{~s}$ intervals were averaged to compensate for intertrial variability and to enable accurate IPSC amplitude measurements. To quantify tail currents, $1 \mathrm{~s}$ trains were applied. The total IPSC current amplitudes were measured as the peak current, evoked by the stimulation, relative to the holding current preceding each train (see Fig. 8). Next, phasic IPSC currents were measured at the peak current relative to each stimulus ("foot-to-peak" IPSCs). The persistent component was obtained as the difference between total and phasic IPSCs. Both total and persistent current amplitude were normalized to the peak IPSC amplitude measured after the first stimulus. The charge transfer was measured as the area underneath the curve at the end of the first IPSC, at the end of the 10th response, and over a $100 \mathrm{~ms}$ period at all frequencies. The charge transfer ratios were then calculated by dividing the charge transfer after the 10th response or after $100 \mathrm{~ms}$ of recording time by the value of the charge transfer of the first response.

\section{MPFA}

Multiple probability fluctuation analysis was performed using a multinomial quantal model, assuming nonuniform $q$, but uniform $p$ values (Silver, 2003; Biró et al., 2006). The analysis was performed separately for each individual cell (see Fig. $7 A 2, B 2$ ), and average quantal parameters were calculated from all cells (see Fig. $7 C, D$ ). Cells were only included into MPFA when criteria for recording stability described above were fulfilled. Then, series of nRT- or APT-IPSCs (50-100 sweeps) were acquired for three different release probabilities per recording. A stability test to determine the maximal contiguous time-stable stretch of data (at a given release probability) was performed using Spearman Rank order analysis, as implemented in the MPFA procedure of the NeuroMatic module (J. S. Rothman and R. A. Silver, UCL, London, UK) written for Igor Pro 5.0.5.7 (Wavemetrics). Typically, at least 50-90\% of the sweeps were included in the analysis. For each sweep, current values were determined from averaged data points, measured in $2 \mathrm{~ms}$ windows before the stimulation artifact (baseline) and at the peak. Individual IPSC amplitude was then calculated as the difference between the baseline and the peak current values, and the mean IPSC amplitude was obtained from the average across sweeps. The variance of IPSC amplitudes was calculated by subtracting baseline variance from peak variance. For each mean/variance pair at a given release probability, the sample error $\sigma_{\text {var }}$ was calculated using $h$ statistics (Silver, 2003; Saviane and Silver, 2006). A plot of the variance against the mean IPSC was then fitted using a simple binomial model, with the contribution of each data point weighted by $1 / \sigma_{\text {var }}{ }^{2}$. From this fit, $N$ and $q$ can be determined and the total $\left(\mathrm{CV}_{\mathrm{T}}\right)$, intrasite $\left(\mathrm{CV}_{\mathrm{I}}\right)$, and intersite $\left(\mathrm{CV}_{\mathrm{II}}\right)$ coefficients of variation calculated. The $\mathrm{CV}_{\mathrm{T}}$ was determined at low release probability $\left(0.5 \mathrm{mM} \mathrm{Ca}^{2+} / 8 \mathrm{~mm}\right.$ $\mathrm{Mg}^{2+}$ ), at which the failure rate was $>70 \%$. From the failure rate and the $\mathrm{N}$ obtained from the binomial fit, we calculated the number of multiquantal events $(m)$ within the successes and the $m$ largest successful events were discarded. The $\mathrm{CV}_{\mathrm{T}}$ of the remaining events was calculated according to $\mathrm{CV}_{\mathrm{T}}=\mathrm{SD}_{0.5 \mathrm{Ca}} / I_{0.5 \mathrm{Ca}}$. To estimate $\mathrm{CV}_{\mathrm{I}}$, we determined an upper limit for $\mathrm{CV}_{\mathrm{I}}\left(\mathrm{CV}_{\mathrm{I}}=\mathrm{SQRT}\left(\sigma^{2} / N\right) / q\right)$ by using amplitude populations obtained at the highest release probabilities (for $8 \mathrm{mM} \mathrm{Ca}^{2+} / 0.5$ $\left.\mathrm{mM} \mathrm{Mg}{ }^{2+}\right)$. Type II CV $\left(\mathrm{CV}_{\mathrm{II}}\right)$ was then obtained via $\mathrm{CV}_{\mathrm{II}}{ }^{2}=\mathrm{CV}_{\mathrm{T}}{ }^{2}-$ $\mathrm{CV}_{\mathrm{I}}{ }^{2}$. The variance-mean plot was fitted using a multinomial quantal model $\sigma^{2}=\left(q I-I^{2} / N\right)\left(1+\mathrm{CV}_{\text {II }}^{2}\right)+q I \mathrm{CV}_{\mathrm{I}}^{2}$ with the contribution of each data point weighted by $1 / \sigma_{\mathrm{var}}{ }^{2}$.

Computational simulations were performed with Fortran-77. One hundred release events were generated by the experimental $N$ and $p$ values for a given cell using binomial statistics, and $q$ values were attrib- 

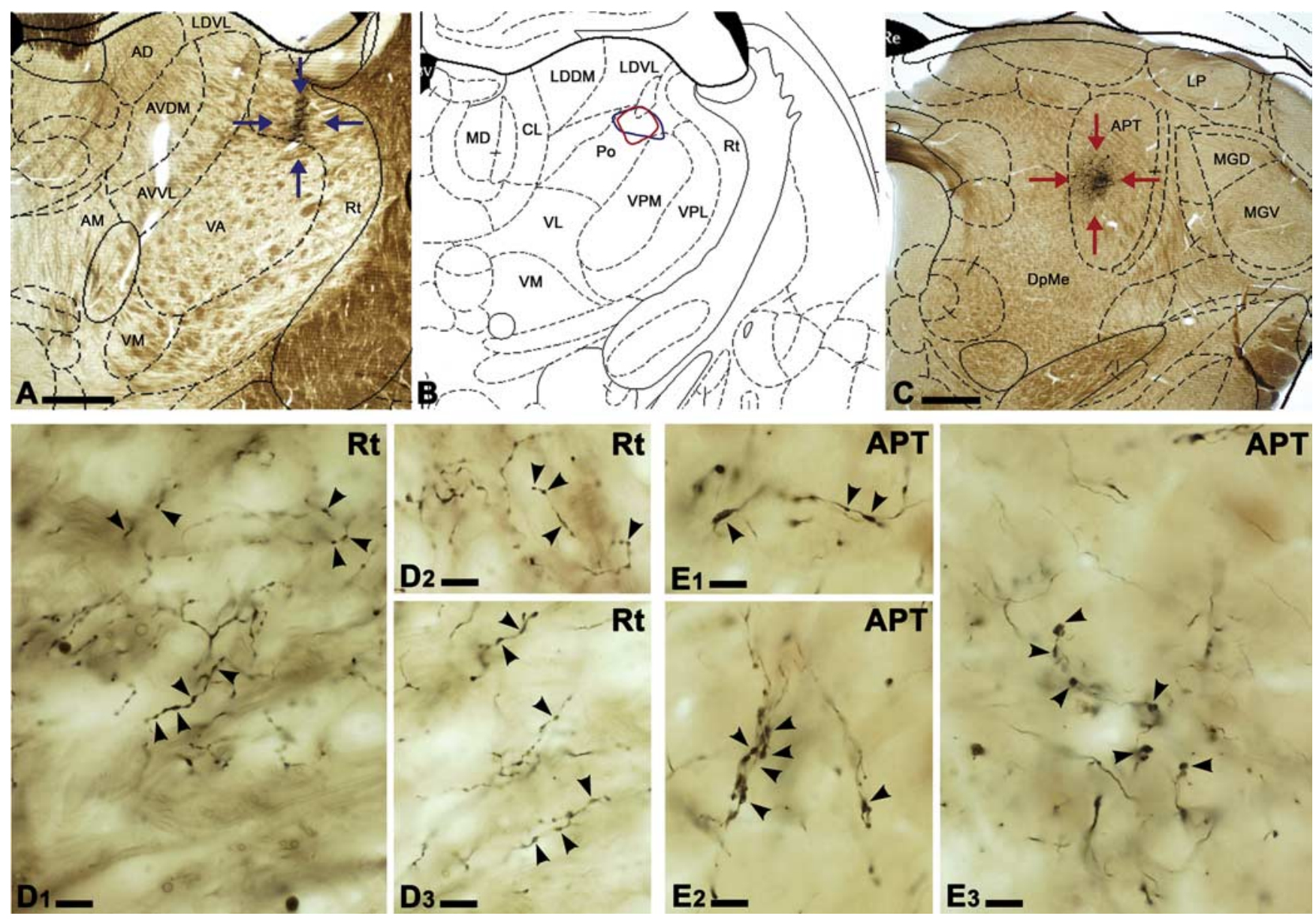

Figure 1. Injection sites and termination zones of the nRT-thalamic and APT-thalamic pathways. $\boldsymbol{A}, \boldsymbol{C}$, Injection sites in the nRT (A, blue arrows) and in the APT (C, red arrows). Mapping of the termination zone is shown in $\boldsymbol{B}$ with the same color coding. Note that the dense terminal labeling overlaps in the dorsolateral part of the Po. D1-D3, E1-E3, The small nRT terminals (D1-D3, arrowheads) are evenly spaced along the axons, whereas the larger APT boutons form clusters (E1-E3, arrowheads). AD, Anterodorsal thalamic nucleus; AM, anteromedial thalamic nucleus; AVDM, AVVL anteroventral thalamic nucleus dorsomedial and ventrolateral part; $\mathrm{CL}$, centrolateral thalamic $\mathrm{n}$; DpMe, deep mesencephalic nucleus; LDDM, LDVL laterodorsal thalamic nucleus dorsomedial and ventrolateral part; $\mathrm{LP}$, lateral posterior thalamic nucleus; $M D$, mediodorsal thalamic nucleus; $M D G, M G V$ medial geniculate nucleus dorsal and ventral part; VA, ventral anterior thalamic nucleus; $\mathrm{VL}$, ventrolateral thalamic nucleus; VM, ventromedial thalamic nucleus; VPM, ventral posteromedial thalamic nucleus; VPL, ventral posterolateral thalamic nucleus. Scale bars: $\boldsymbol{A}-\boldsymbol{C}, 500 \mu \mathrm{m}$. $\boldsymbol{D}-\boldsymbol{E}$, $10 \mu \mathrm{m}$.

uted for each event by random selection from a Gaussian distribution around the mean and SD of successes at low release probability.

\section{Statistics}

The physiological data presented are expressed as mean \pm SEM, and statistical significance was determined with paired or unpaired Student's $t$ tests.

\section{Drugs}

Standard solution components were obtained from Sigma-Aldrich, except QX-314 (Alomone Labs), TTX (Latoxan), DNQX, and D,L-APV (Tocris Bioscience).

\section{Results}

\section{The nRT-thalamic and the APT-thalamic pathways}

Tracer injection into the head of the nRT and the middle part of APT labeled axon terminals in overlapping regions of Po (Fig. $1 A-C$ ), confirming previous results (Pinault and Deschênes, 1998; Bokor et al., 2005). The nRT axons branched profusely and were studded with large number of small varicosities distributed evenly along the individual branches (Fig. 1D1-D3). In contrast, APT terminals were medium to large in size, and long, boutonfree segments alternated with small clusters of terminals, resulting in uneven intervaricose distances (Fig. 1E1-E3).

\section{Ultrastructure of $\mathrm{nRT}$ and APT terminals}

In the following electron microscopic account, "synapse" will refer to a circumscribed membrane specialization including the presynaptic and postsynaptic densities, the vesicles and the cleft. Synaptic specializations, which appeared noncontinuous after $3 \mathrm{D}$ reconstructions, were treated as separate synapses. "Active zone" is the presynaptic component of the synapse. PA (also known as filamentous contacts) are distinct from synapses, in that they have thick, asymmetric membrane specializations and lack vesicle accumulation, as described before (Lieberman and Spacek, 1997; Bodor et al., 2008).

Of the 78 anterogradely labeled nRT and 102 APT profiles, the number of active zones was established in 41 and 29 cases, respectively. The size of the terminals was determined in $22 \mathrm{nRT}$ and in 36 APT boutons. Twenty-five nRT and 47 APT terminals were partially reconstructed. All profiles included in the analysis were GABA-positive. For a detailed description of the database, see Materials and Methods section.

In single electron microscopic sections, both nRT and APT terminals established conventional symmetrical synapses, containing flattened, pleomorph vesicles and several mitochondria, 

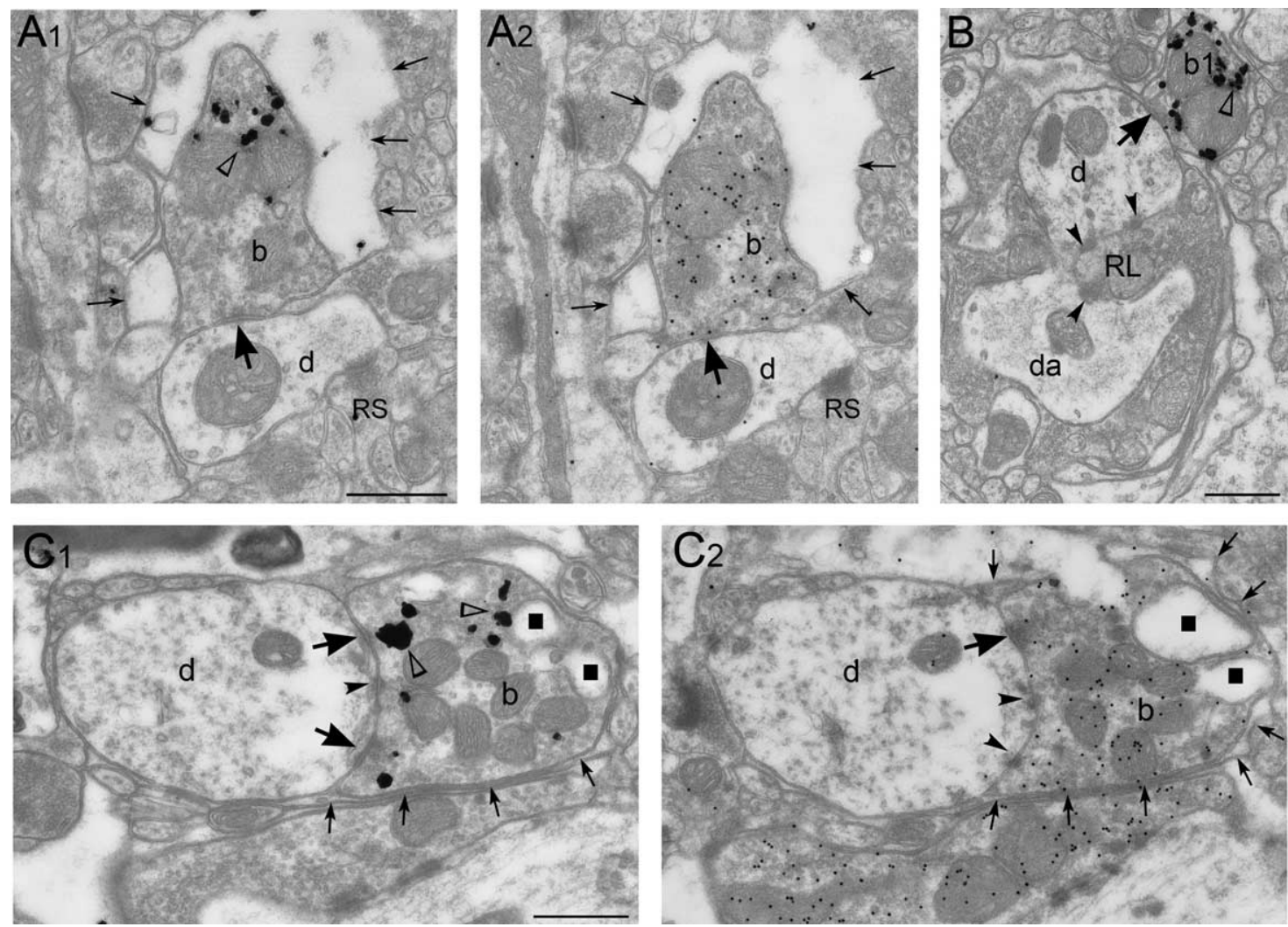

Figure 2. Ultrastructural features of nRT-thalamic and APT-thalamic terminals in the Po nucleus of rat. $\boldsymbol{A}-\boldsymbol{C}$, High-power electron microscopic images showing two anterogradely labeled nRT-thalamic $(\boldsymbol{A}, \boldsymbol{B})$ and an APT-thalamic terminal (C). $\mathbf{A} \mathbf{2}$ and $\mathbf{C}$ are the neighboring sections to $\boldsymbol{A} \mathbf{1}$ and $\mathbf{C}$, respectively, postembedding immunoreacted for GABA (small black dots). Silver intensified gold particles (empty triangles) indicate the anterograde tracer. The $n R T$ terminals form single synapses (thick arrows in $\boldsymbol{A} \mathbf{1}, \boldsymbol{A} \mathbf{2}$, and $\boldsymbol{B}$ ) on their targets, which are a thin dendrite receiving unlabeled RS-type terminal in $\boldsymbol{A} \mathbf{1}$ and $\boldsymbol{A} \mathbf{2}$ and a thick dendrite contacted by RL-type terminal in $\boldsymbol{B}$. The APT terminal forms multiple synapses (thick arrows in $\mathbf{C 1}, \mathbf{C}$ ) and puncta adhaerentia (arrowheads) on a thick dendrite. Three-dimensional reconstruction of the terminal in $\boldsymbol{B}$ and $\boldsymbol{C}$ is shown in Figure 3, $\boldsymbol{A} \mathbf{1}$ and $\mathbf{C 1}$, respectively. Note that in $\boldsymbol{A 2}$ and $\mathbf{C 2}$, the anterograde signal is absent as a result of the etching procedure of the postembedding GABA immunostaining. $d$, Dendrites; b, boutons; thin arrows, glial covering; black square in $C 1$ and $\mathbf{C} 2$, glia intruding into the APT terminal; $\mathrm{da}$, dendritic appendage. Scale bars, $0.5 \mu \mathrm{m}$.

as previously reported (Montero, 1983; Cucchiaro et al., 1991; Liu et al., 1995b; Bokor et al., 2005) (Figs. 2, 3A2-A7,C2-C8).

\section{Difference in size and postsynaptic targets between nRT-} thalamic and APT-thalamic terminals

The median volume of nRT boutons was $0.47 \mu \mathrm{m}^{3}$ (interquartile range, $0.43-0.6 \mu \mathrm{m}^{3} ; n=22$ ). The same value of their longest diameters was $1.84 \mu \mathrm{m}$ (interquartile range, 1.55-2.18 $\mu \mathrm{m}$ ). APT terminals were at least five times larger (median volume, 2.4 $\mu \mathrm{m}^{3}$; interquartile range, $\left.1.59-3.55 \mu \mathrm{m}^{3} ; n=36\right)$ and $50 \%$ longer (median of their longest diameters, $2.77 \mu \mathrm{m}$; interquartile range, $1.55-3.77 \mu \mathrm{m})$ than nRT terminals. The size difference was statistically highly significant both for the volume and for the longest diameter ( $p<0.01$, Mann-Whitney $U$ test).

The minor diameters of the postsynaptic elements of APT and nRT terminals were compared with each other and to a random sample of the neuropil ( $n=398)$ obtained from Po (Fig. $4 A)$. As expected, the neuropil of Po was mainly composed of thin caliber dendrites. Eighty-five percent of the minor diameters in the random samples were $<0.8 \mu \mathrm{m}$. The distribution of $\mathrm{nRT}$ postsynaptic elements was similar to the random sample (Fig. 4A), 71\% of the postsynaptic dendrites contacted by nRT terminals were thinner than $0.8 \mu \mathrm{m}$. The median values of the minor diameters of the nRT targets $(0.65 \mu \mathrm{m})$ were very close to the median of the random sample $(0.56 \mu \mathrm{m})$. In sharp contrast, the median values of APT targets were twice as large as $\mathrm{nRT}$ targets and the random sample $(1.38 \mu \mathrm{m})$. Eighty-eight percent of the Po dendrites con- tacted by APT terminals were thicker than $0.8 \mu \mathrm{m}$, showing significant target selectivity for thick dendrites. The difference between the postsynaptic target distribution of nRT and APT terminals was statistically significant ( $p<0.001, \chi^{2}$ test).

To determine if thick dendrites in our sample indeed represent proximal dendrites in functional terms as well, the types of unlabeled excitatory terminals contacting the dendrites postsynaptic to nRT and APT boutons were categorized. The neuropil of the thalamus consists of two types of GABA-negative, excitatory terminals (Sherman and Guillery, 2006). The small terminals (RS) innervate distal dendrites, whereas the large terminals (RL) targets proximal dendrites and have strong impact on the firing activity of the postsynaptic cell, serving as "driver inputs" (Guillery and Sherman, 2002). Based on the well established ultrastructural criteria, the overwhelming majority (90.2\%) of dendrites contacted by nRT terminals received RS-type boutons and only $8.8 \%$ were contacted by RL terminals (Figs. $2 A, B, 4 B$ ). In sharp contrast, RL type terminals formed synapses on $75.4 \%$ of dendrites innervated by APT terminals (Fig. $4 \mathrm{~B}$ ). These data demonstrate that $\mathrm{nRT}$ terminals contact all dendritic domains in proportion of their occurrence, whereas APT terminals preferentially innervate proximal dendritic domains contacted by the giant driver inputs.

\section{Difference in synaptic organization between nRT-Po and APT-Po boutons}

$3 \mathrm{D}$ electron microscopic reconstruction demonstrated a striking difference between the $\mathrm{nRT}$ and the APT boutons with respect to 

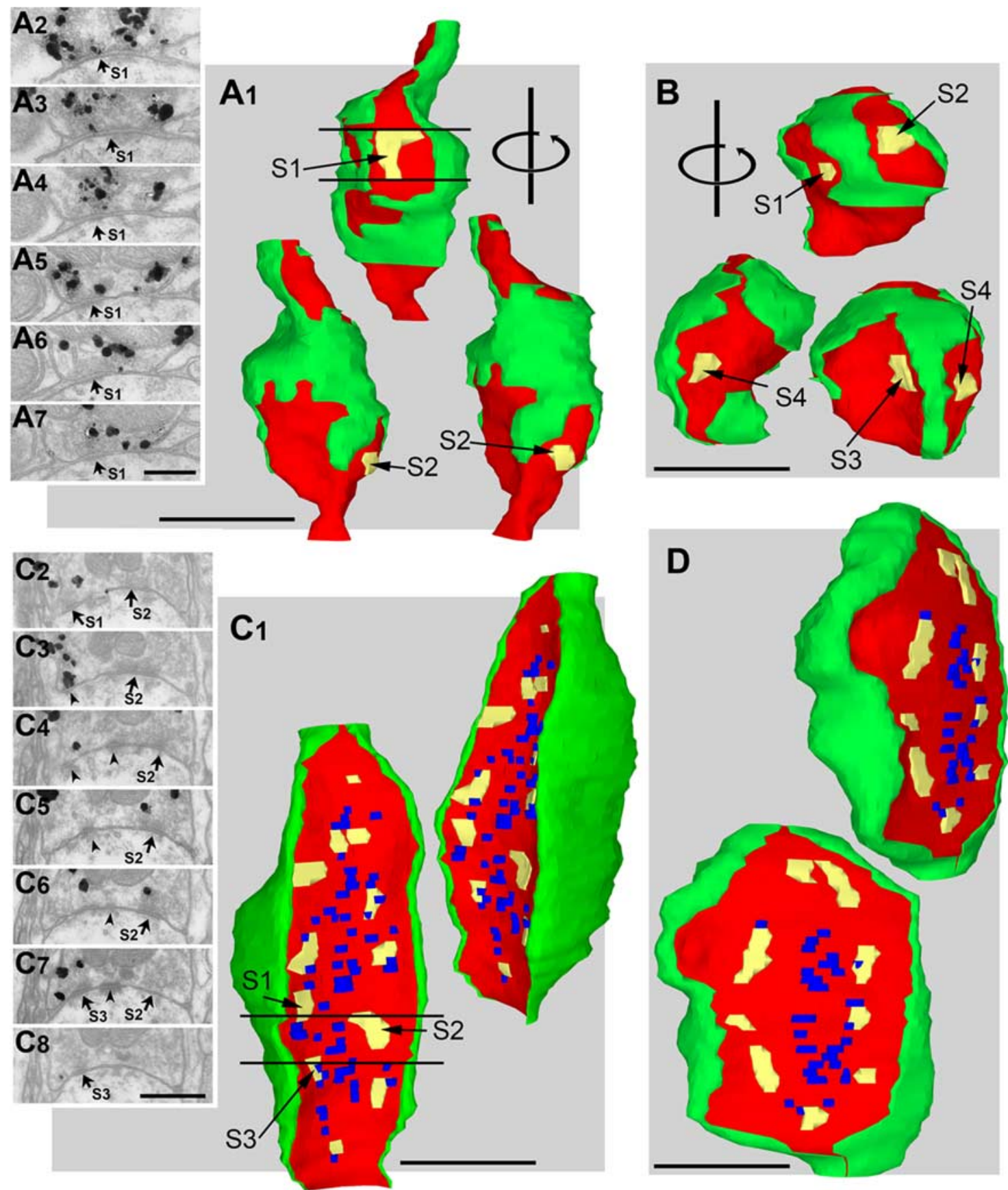

Figure 3. Three-dimensional reconstructions of $n R T$-and APT-thalamic terminals. $A, B$, Three views of two nRT terminals in Po. Both terminals have multiple synapses (yellow, $S 1-S 4$ ), which face different directions. Each synapse is separated by glial processes (green) and innervates different dendrites (data not shown). Serial EM images ( $\boldsymbol{A} \mathbf{2}-\boldsymbol{A} \mathbf{7})$ through the symmetrical synapse S1 in $\boldsymbol{A} \mathbf{1}$ demonstrate single uninterrupted postsynaptic specialization (arrows). C, D. Two views of two APT-thalamic terminals. In sharp contrast to nRT terminals, all synapses of a single terminal (12 in $\boldsymbol{C}$, 9 in D) face one direction and innervate a single dendrite (data not shown). Note that the synapses are organized around a centrally placed network of PA (blue). Glial processes do not separate the

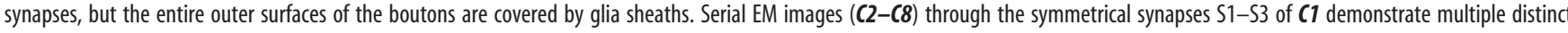
postsynaptic specialization (arrows) and PA (arrowheads). Red, Membrane of the terminal. Scale bars: A1, B, C1, D, $1 \mu \mathrm{m} ; \mathbf{A 2}-\mathbf{A 7}, \mathbf{C 2}-\mathbf{C} 8,0.5 \mu \mathrm{m}$.

the number of synapses a given terminal establishes with its postsynaptic partner. Three parameters were examined: (1) the number of active zones per terminal, (2) the number of postsynaptic targets a given terminal contacts, and (3) the number of synapses a given terminal establishes with its individual partner(s).

The median number of active zones in case of nRT terminals was two (mean, $2.1 ; n=41$ ). Eleven of the forty-one nRT terminals $(26.8 \%)$ had single active zones (hence, obviously a single target). The rest of the nRT terminals $(n=30)$ had $2-5$ active zones. Most of the nRT terminals with multiple active zones $(80 \%)$ contacted more than one postsynaptic partner (2-4) (Fig. $3 A, B$; supplemental Movie S1, available at www.jneurosci.org as supplemental material). The majority of the dendrites $(80.6 \%$; $n=72$ targets) postsynaptic to nRT terminals were innervated by a single synapse. The mean number of synapses an nRT terminal established with a given target was 1.21 (median 1). When followed in serial electron microscopic sections, the dendrites contacted by a single nRT terminal diverged in different directions; thus, they probably belonged to different dendritic trees. 
A

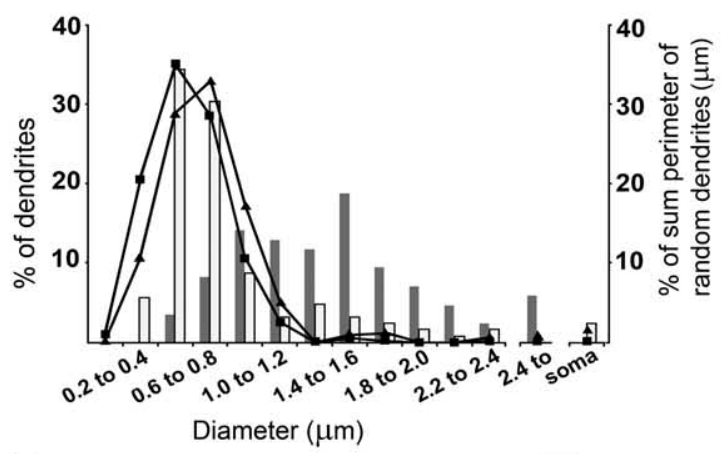

D

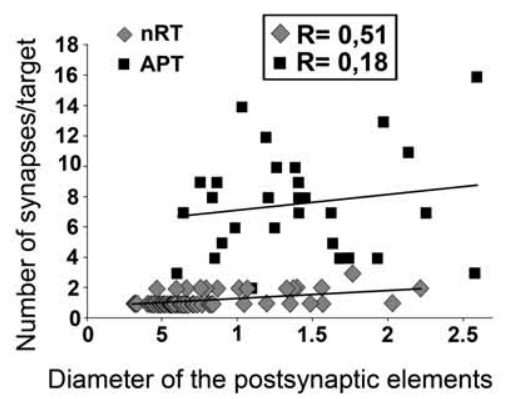

B

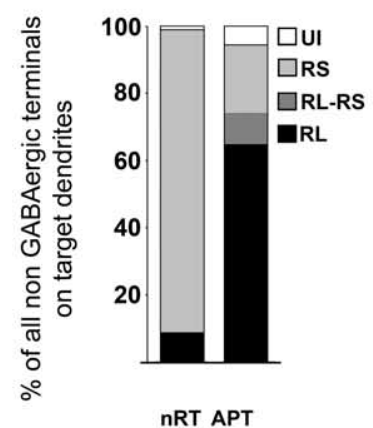

nRT APT
C

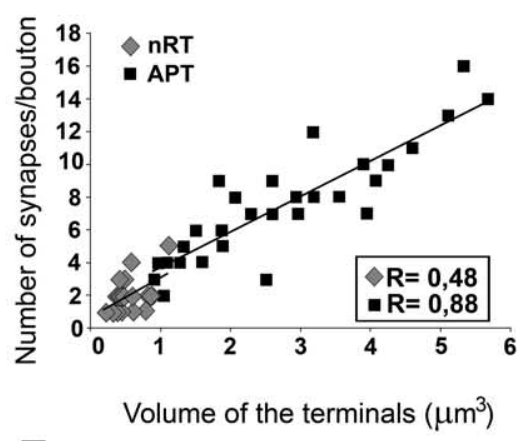

$\mathbf{F}$

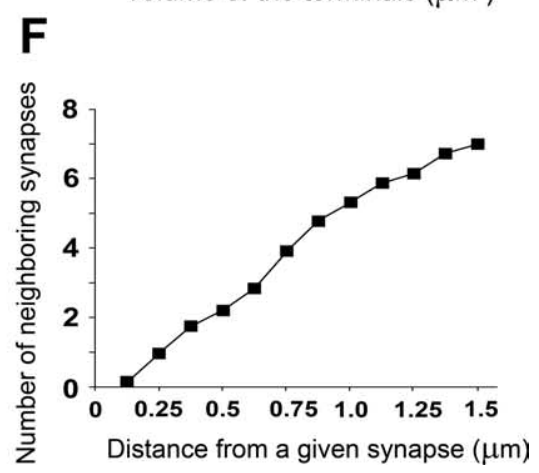

Figure 4. Quantitative analysis of the APT and nRT terminals and their targets in Po. A, Comparison of random dendritic diameters to the diameter of targets postsynaptic to nRT-thalamic (white bars; $n=84$ ) and APT-thalamic (gray bars; $n=125$ ) terminals. The distribution of the random dendrite diameters is shown in two ways: as the percentage of dendrites in each bin (black line with squares; left $y$-axis) and as the percentage of summated perimeter of the dendrites in each bin (black lines with triangles; right $y$-axis). The first one is used for statistical comparison, whereas the second one better represents the available target surfaces. APT target diameters are skewed toward the larger values, whereas the nRT targets and the random sample overlap. $\boldsymbol{B}$, Analysis of non-GABAergic terminal types on the dendrites contacted by nRT (first column) or APT (second column) boutons. Note the contrasting pattern of RL and RS inputs in dendrites innervated by nRT and APT terminals. For the description of RL and RS terminals, see Results, Difference in size and postsynaptic targets between nRT-thalamic and APT-thalamic terminals. RL-RS, Both types of input; UI, unidentified. C, Correlation between the volume of the terminals and the number of synapses an individual terminal establishes. Lines represent the linear regression. Note the clear separation of nRT and APT boutons along both the $x$ - and $y$-axes. D, Correlation between the diameter of the postsynaptic elements (excluding somatic targets) and the number of synapses a terminal establishes with a given target. nRT data, Gray diamonds; APT data, black squares. $\boldsymbol{E}$, Cumulative distribution of nearest neighbor synaptic distances in APT terminals. $\boldsymbol{F}$, The average number of APT synapses with increasing distances from a given synapse belonging to a single bouton.

Compared with nRT terminals, the number of active zones/ terminal was severalfold higher for APT terminals (mean, 7.55; median, 7; interquartile range, $5-9$; $\min -\max , 2-16$; $n=29$ ). All synapses of single APT terminals $(n=29)$ converged on the same postsynaptic profile. Thus, the mean number of synapses a terminal established with a single postsynaptic partner was also 7.55 (median 7). This means that a single APT terminal forms, on average, seven times more synapses on a single target than an nRT terminal.

The synapses of APT boutons were organized in a circular manner around a centrally localized network of PA (Fig. 3C1-D; supplemental Movie S2, available at www.jneurosci.org as supplemental material). Such a PA network was never observed in case of nRT terminals. Almost all APT synapses were localized on dendritic shafts; contacts on dendritic protrusions were found only in one case. More than one large APT terminal, each with multiple synapses, frequently converged on the same dendrite. APT-thalamic terminals displayed similar properties in 18-d-old animals (supplemental Fig. S1, available at www.jneurosci.org as supplemental material) than in the adults.

For both inputs, the number of synapses correlated with the volume of the terminals (Fig. 4C), suggesting that terminal size is proportional to synaptic strength (Xu-Friedman and Regehr, 2004). This correlation reached statistical significance only in the case of APT (one-way ANOVA; $p<0.001$ ). However, the diam- eter of the postsynaptic elements and the number of synapses established by an individual terminal did not correlate (Fig. 4D). The surface area of the synaptic specialization showed great heterogeneity in both pathways, but the range (min-max: 0.014$0.087 \mu \mathrm{m}^{2}, n=17$; min-max: $0.014-0.092 \mu \mathrm{m}^{2}, n=43$ for nRT and APT, respectively) and the mean values ( $\left.0.048 \mathrm{vs} 0.040 \mu \mathrm{m}^{2}\right)$ were similar.

Finally, the glial cover and the intersynaptic distances were examined in the two bouton populations. 3D reconstruction revealed that nRT terminals never displayed complete glial sheath on their outer surface. Glial lamellae separated the synapses of nRT terminals contacting different dendrites, but in the few cases where multiple nRT synapses contacted the same target, the synapses were not separated by glia. Of the 22 nRT boutons (45 synapses) examined, 5 terminals (11 synapses) formed multiple contacts on the same dendrite, without glial lamellae. Since glia is considered to be a diffusion barrier, the intersynaptic distance was measured only in this small set of synapses (median, $347 \mathrm{~nm}$; $n=7$ distances).

In contrast to nRT boutons, the entire outer surface of the APT terminals had complete glial cover. The other major difference compared with nRT terminals was that almost all intersynaptic spaces of APT terminals were free of glia. In a few cases ( 3 of 29 boutons), glial lamellae separated the synaptic surfaces into two parts, but even in these terminals most of the synapses were not separated by glia. 

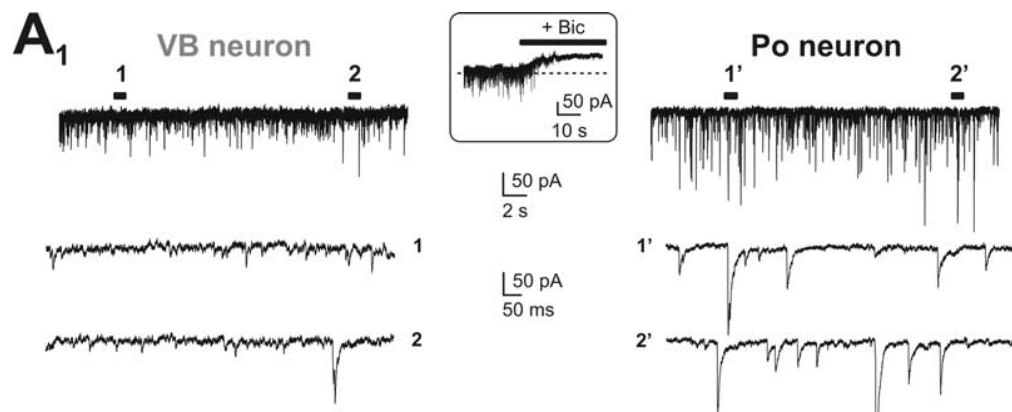

\section{$\lfloor 50 \mathrm{pA}$
$50 \mathrm{~ms}$}

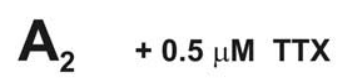

VB neuron

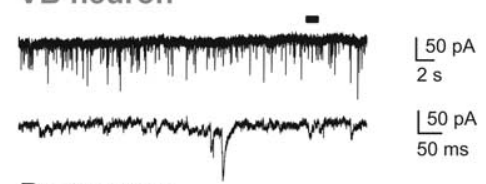

Po neuron
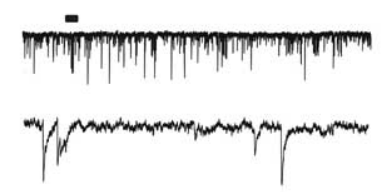

C

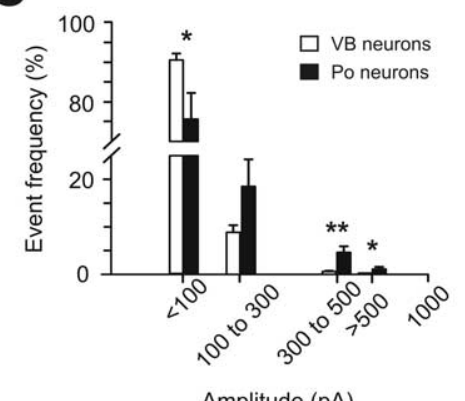

B
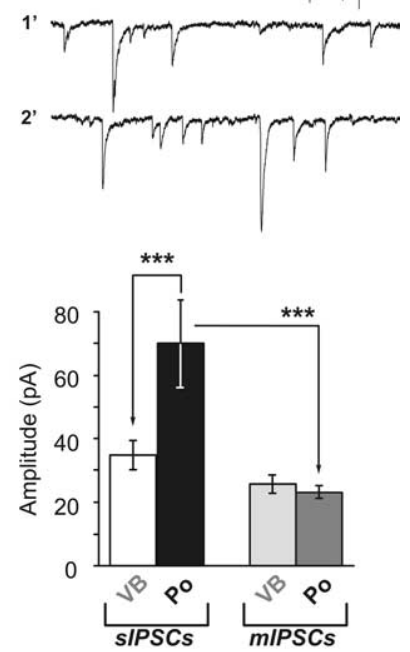

D
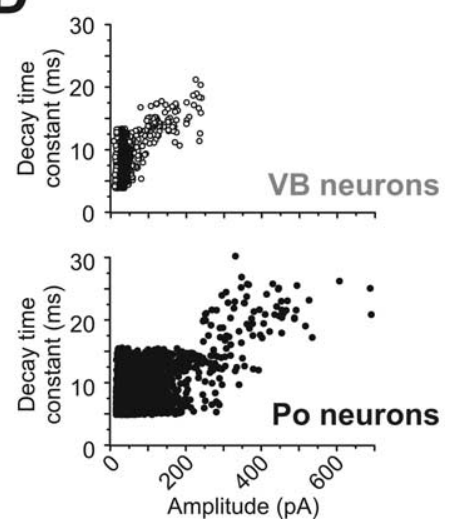

Figure 5. Larger and slower sIPSCs in Po compared with VB. A, Raw sIPSCs (A1) and mIPSCs (A2) for representative VB and Po neurons. A 30 s long recording is shown at the top of each section. Expanded portions, selected from the areas labeled with numbers (A1; sIPSCS) and with black bars (A2; mIPSCs), are presented below. TTX (0.5 $\mu \mathrm{m})$ was applied to isolate mIPSCs. Inset, Membrane current response of a Po neuron to bath application of the $\mathrm{GABA}_{\mathrm{A}}$ receptor antagonist bicuculline (+Bic, $\left.25 \mu \mathrm{M}\right)$. $\boldsymbol{B}$, Histogram of average sIPSC ( $n=10$ for VB, $n=9$ for Po) and mIPSC amplitudes ( $n=8$ for VB, $n=9$ for Po). ${ }^{* * *} p<0.001$. C, Histogram of the frequency distribution for sIPSC amplitudes binned by their size, as indicated on the abscissa. ${ }^{*} p<0.05$; ${ }^{* *} p<$ 0.01. D, Distribution of sIPSC decay time constants as a function of sIPSC amplitude. Data were pooled from 10 VB and 9 Po neurons. Note slower decay of the large events in Po.

APT synapses were closely spaced to each other. The median value of the nearest neighbor distances between APT synapses was $204 \mathrm{~nm}$ (interquartile range, $171-243$ ) and $77.8 \%$ of the nearest neighbor distances was $<300 \mathrm{~nm}$ (Fig. $4 E$ ). On average, every synapse had at least 5 neighboring synapses (5.32) within 1 $\mu \mathrm{m}$ distance (Fig. $4 F$ ).

The anatomical data show strikingly different morphological organization of the two GABAergic pathways. The small nRT terminals innervate the entire dendritic tree mostly via single synapses, whereas the large APT terminals innervate proximal dendrites via multiple synapses. To compare and investigate the physiological properties of the two GABAergic afferents, spontaneous and evoked inhibitory events were examined in a horizontal slice preparation, containing both the nRT- and the APTthalamic pathways.

\section{Spontaneous inhibitory events in} thalamic nuclei

The inhibitory events generated by $\mathrm{nRT}$ and APT were compared by monitoring spontaneous synaptic activity in relay cells of the $\mathrm{VB}$ and of Po. This latter nucleus receives both reticular and extrareticular inputs (Barthó et al., 2002; Bokor et al., 2005), whereas VB is innervated by nRT only (Liu et al., 1995a; Pinault et al., 1995). In neurons from both nuclei, voltage-clamped at $-60 \mathrm{mV}$ and perfused with high $\mathrm{Cl}^{-}$-containing recording solutions, spontaneous inward currents persisted in the presence of blockers of excitatory synaptic transmission but were antagonized by the $\mathrm{GABA}_{\mathrm{A}}$ receptor antagonist bicuculline ( $25 \mu \mathrm{M} ; n=3$ for both VB and Po) (Fig. 5A1, inset shown for Po). The amplitudes of sIPSCs reached absolute values up to $202 \pm 9 \mathrm{pA}$ in VB cells (range of maximal values, $172-245 \mathrm{pA} ; n=10)$ and up to $516 \pm 43 \mathrm{pA}$ in Po (range of maximal values, 306-691 pA; $n=9 ; p<0.001$ ) (Fig. 5A1). On average, amplitudes of sIPSCs were about twofold smaller in VB than in Po (VB: $35 \pm 5 \mathrm{pA}, n=10$; Po: $70 \pm 15 \mathrm{pA}, n=9$, $p<0.001$ ) (Fig. 5A1,B, left). Binned histograms demonstrated that small amplitude events $(<100 \mathrm{pA})$ dominated in $\mathrm{VB}(p<$ 0.05 ), whereas large amplitude events were present at a greater fraction in the total sIPSC population of Po (e.g., for events with amplitude between 300 and $500 \mathrm{pA}: 4.6 \pm 1.3 \%$ in Po, $0.6 \pm 0.2 \%$ in VB; $p<0.01$ ) (Fig. $5 C$ ). In the presence of $0.5 \mu \mathrm{M}$ TTX (Fig. 5A2), the mIPSCs had an average absolute amplitude of $26 \pm 3 \mathrm{pA}$ in $\mathrm{VB}(n=8)$ and $23 \pm 2 \mathrm{pA}$ in Po $(n=9 ; p>0.05)$ (Fig. $5 B)$. These values are similar to the mean sIPSC amplitudes in $\mathrm{VB}(p>0.05)$, but they are smaller than in Po $(p<0.001)$ (Fig. $5 B$, right). Thus, in both $\mathrm{VB}$ and $\mathrm{Po}$, events with high quantal content (up to maximally $\sim 10$ in VB and $\sim 30$ in Po) could be observed, but these large events appeared more prominently in Po. To test whether these could arise from a distinct inhibitory source, we examined how the waveform of sIPSCs varied with its amplitude. We found that the $10 \%$ largest events in Po showed distinctly greater monoexponential time constants of decay $(\tau)$ than the $10 \%$ smallest events $(\tau=18.0 \pm 0.4 \mathrm{~ms}, n=272$, vs $5.9 \pm 0.1 \mathrm{~ms}, n=272$; $p<$ 0.001 ) (Fig. $5 D$ ), whereas the decay time constant of the $10 \%$ largest and $10 \%$ smallest events in VB amounted to $10.4 \pm 0.3 \mathrm{~ms}(n=213$; $p<0.001$ compared with largest APT events) and $5.8 \pm 0.1 \mathrm{~ms}(n=$ $213 ; p<0.001$ compared with largest events in VB), respectively. Thus, although events recorded in VB and Po showed similar amplitude and kinetics for the smallest amplitudes, large events with slow decay were recorded exclusively from Po.

\section{Evoked IPSCs in the Po nucleus}

Both reticular (Crabtree et al., 1998; Lam and Sherman, 2007), as well as extrareticular (Bokor et al., 2005) afferent projections onto Po can be preserved in the same horizontal brain slice. Uni- 
tary inhibitory synaptic responses in voltage-clamped Po neurons were evoked electrically using a bipolar electrode placed within nRT or APT (see Materials and Methods). Such stimuli elicited IPSCs with all-or-none response characteristics (supplemental Figs. S2, S3A, available at www.jneurosci.org as supplemental material), a fixed latency (supplemental Fig. $\mathrm{S} 3 B$, available at www.jneurosci.org as supplemental material), and a monophasic rise $[10-90 \%$ rise time, $0.53 \pm 0.08 \mathrm{~ms}$ and $0.77 \pm 0.19 \mathrm{~ms}$ for $\mathrm{nRT}(n=5)$ and APT $(n=7)$ representative cells, respectively; $p>0.05$ ], indicating unitary connectivity.

Both unitary nRT-IPSCs and APTIPSCs increased in amplitude when release probability was enhanced by augmenting the $\mathrm{Ca}^{2+} / \mathrm{Mg}^{2+}$ ratio (Fig. 6A) and reached a plateau when the $\mathrm{Ca}^{2+} / \mathrm{Mg}^{2+}$ ratio was $4 \mathrm{~mm} / 0.5 \mathrm{~mm}$ (ratio 8 ), with further increases to $\mathrm{Ca}^{2+} / \mathrm{Mg}^{2+}=8 \mathrm{~mm} / 0.5$ $\mathrm{mM}$ (ratio 16) not significantly enhancing current amplitudes $(p>0.05$ for both nRT and APT) (Fig. 6B) (Schneggenburger et al., 1999). Such manipulations did not alter the recording quality of the postsynaptic cell (Fig. 7A2,B2, bottom) (Materials and Methods). IPSCs evoked in nRT showed smaller response amplitudes than APT-IPSCs throughout the major range of $\mathrm{Ca}^{2+} / \mathrm{Mg}^{2+}$ ratios (Fig. $6 B, C$ ). At plateau levels, nRT-IPSCs reached about half the amplitude of APT-IPSCs, with absolute values averaging $109 \pm 7 \mathrm{pA}(n=$ $5)$, whereas APT-IPSCs were $198 \pm 22 \mathrm{pA}$ $(n=5 ; p<0.01)$. Both response types showed equal half-maximal $\mathrm{Ca}^{2+} / \mathrm{Mg}^{2+}$ concentration ratios $(0.81 \pm 0.21$ and $0.88 \pm 0.08$ for $\mathrm{nRT}$ and APT, respectively) (Fig. $6 \mathrm{~B}$ ), indicating that comparable $\mathrm{Ca}^{2+}$ entry triggers a greater response at APT than nRT synapses. APT-IPSCs decayed more slowly at all release probabilities tested (Fig. 6A,C) and further slowed down after increasing the $\mathrm{Ca}^{2+} / \mathrm{Mg}^{2+}$ ratio $(p<0.05)$. In contrast, nRT-IPSC decay remained unaffected with altered release probability $(p>0.05)$. These findings comply with APT synapses generating unitary responses with a comparatively high number of release events (see Discussion).

\section{Quantal parameters of APT and nRT synapses onto Po cells}

The higher quantal content of APT-IPSCs, accompanied by a comparable sensitivity to $\mathrm{Ca}^{2+}$ entry, could result from a greater number of synaptic contacts or from multivesicular release at APT synapses. We determined quantal parameters of nRT and APT synapses by applying MPFA, also known as variance-mean analysis, to unitary nRT- and APT-IPSCs (Silver, 2003). Timestable series of unitary IPSCs were collected for three different release probability conditions, set by three $\mathrm{Ca}^{2+} / \mathrm{Mg}^{2+}$ ratios (in mм: $2 / 2,0.5 / 4,8 / 0.5)$, to determine the total nonuniformity in quantal size $\left(\mathrm{CV}_{\mathrm{T}}\right)$, as well as the intrasite $\left(\mathrm{CV}_{\mathrm{I}}\right)$ and intersite
$\left(\mathrm{CV}_{\mathrm{II}}\right)$ quantal variabilities (see Materials and Methods) (Silver, 2003). The values for $\mathrm{CV}_{\mathrm{I}}$ and $\mathrm{CV}_{\text {II }}$ were determined in 4 of 12 nRT-Po connections and in 7 of 26 APT-Po connections satisfying stable recording criteria. Changing the $\mathrm{Ca}^{2+} / \mathrm{Mg}^{2+}$ ratio strongly affected response amplitude, response variability and failure rate (Fig. $7 A 1, A 2, B 1, B 2$ ). At the lowest $\mathrm{Ca}^{2+} / \mathrm{Mg}^{2+}$ ratio $(0.5 \mathrm{~mm} / 4 \mathrm{mM})$, the failure rate increased to $>70 \%(86.2 \pm 2.5 \%$, for $\mathrm{nRT}, n=4 ; 83.1 \pm 3.0 \%$ for APT, $n=7 ; p>0.05$ ) with the amplitude of successful responses in the range of 12-17 pA for nRT (average, $16.4 \pm 1.6 \mathrm{pA} n=4$ ) and $10-23 \mathrm{pA}$ for APT (average, $14.5 \pm 1.5 \mathrm{pA} ; n=7)$. In every cell, the number $m$ of putative multiquantal events $(m=2.1 \pm 0.8$ for $n R T ; n=4$ and $3.5 \pm 1.0$ for APT; $n=7$; range $1-8$ ) recorded at the lowest probability (Biró et al., 2006) were eliminated to calculate $\mathrm{CV}_{\mathrm{T}}=$ $0.33 \pm 0.03$ for $\operatorname{nRT}(n=4)$ and $0.31 \pm 0.03$ for $\mathrm{APT}(n=7 ; p>$ $0.05)$. In $8 \mathrm{mM} \mathrm{Ca}^{2+} / 0.5 \mathrm{mM} \mathrm{Mg}^{2+}$, with release probability maximized, the response size increased to $83-162 \mathrm{pA}$ for $\mathrm{nRT}$ and to 

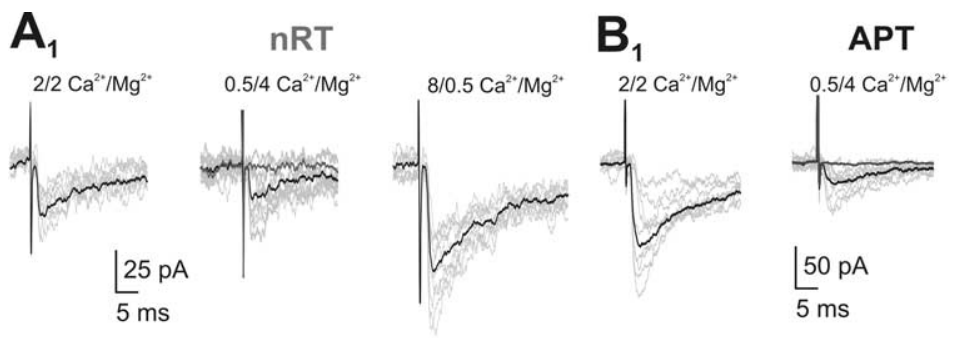

$\mathrm{A}_{2}$
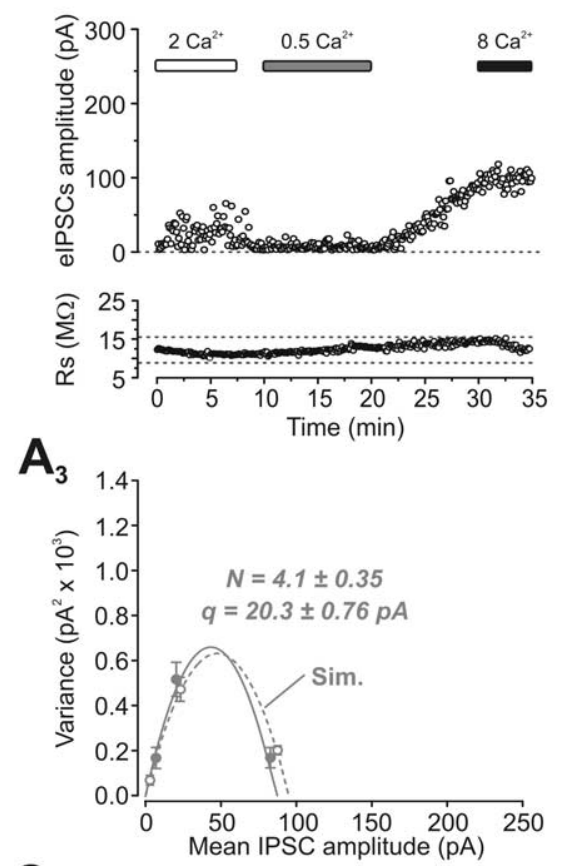

$\mathrm{B}_{2}$

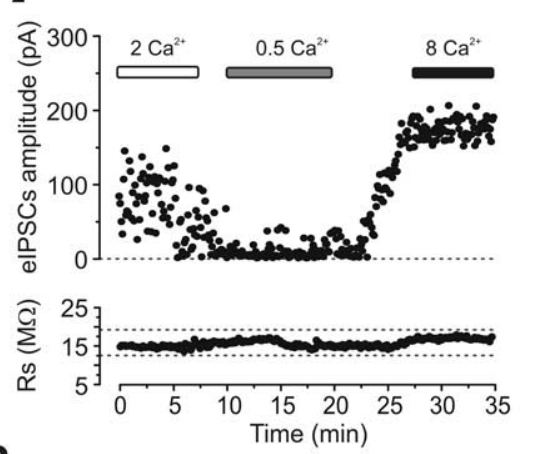

$\mathrm{B}_{3}$
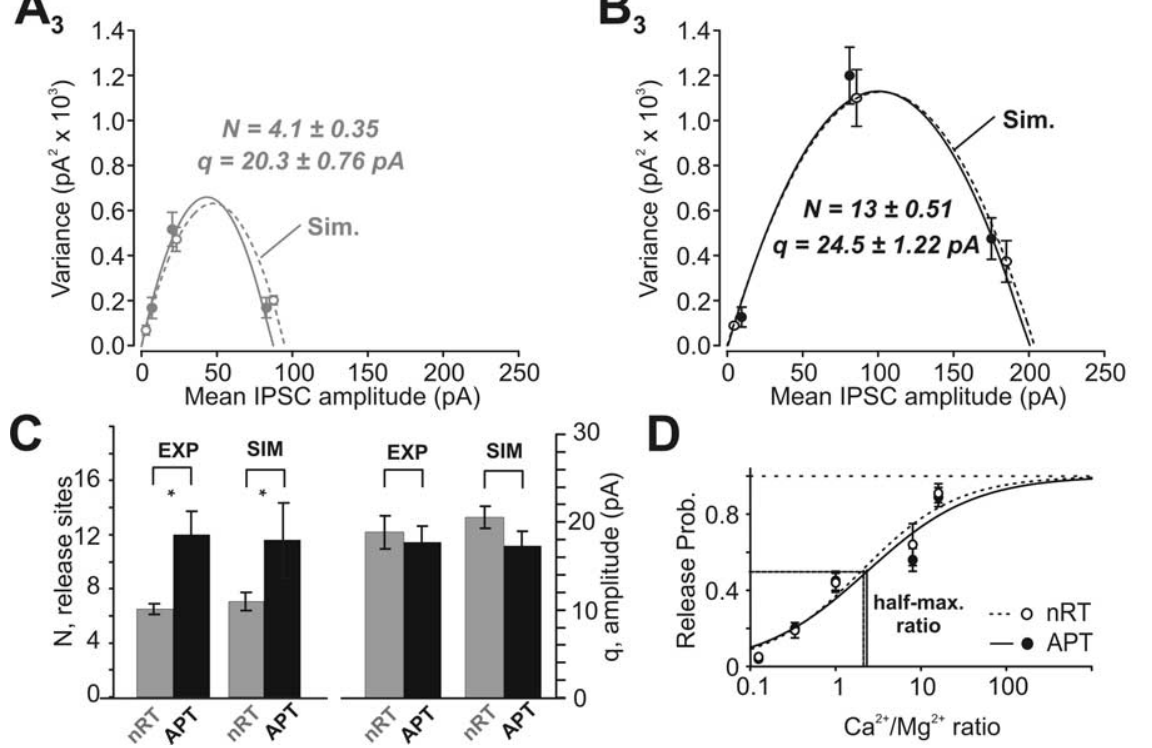

Figure 7. Variance-mean analysis of unitary nRT- and APT-IPSCS. A1, B1, Family of nRT- and APT-IPSCs obtained at different $\mathrm{Ca}^{2+} / \mathrm{Mg}^{2+}$ ratios. For every $\mathrm{Ca}^{2+} / \mathrm{Mg}^{2+}$ ratio, 10 individual sweeps (gray traces) are shown superimposed together with the average of 100 sweeps (black trace). For the $0.5 \mathrm{Ca}^{2+} / 4 \mathrm{mM} \mathrm{Mg}^{2+}$ ratio, the means of the 89 failures recorded for nRT-IPSCs and of the 78 failures for APT-IPSCs are also shown. A2, B2, Time course of evoked IPSC amplitude recordings during successive applications of three different $\mathrm{Ca}^{2+} / \mathrm{Mg}^{2+}$ ratios, indicated above the bars. Corresponding series resistances are shown below, with dashed lines indicating the $\pm 20 \%$ tolerance level. $\boldsymbol{A} \mathbf{3}, \boldsymbol{B} 3$, Variance-mean plot for $\mathrm{nRT}$ - and APT-IPSCs presented in $\boldsymbol{A}$ and $\boldsymbol{B}$, with the weighted fit shown overlaid in continuous lines. The fit from simulated data (sim) is shown in the same plot (dotted lines). C, Average values for $N$ and $q$ obtained from the weighted fit (exp, $n=9$ for $n R T, n=12$ for APT) and from the fit to the simulated data (sim, $n=4$ for $n R T, n=7$ for APT). D, Sigmoidal dependence of release probabilities on the $\mathrm{Ca}^{2+} / \mathrm{Mg}^{2+}$ ratio, as obtained from the variance-mean analysis. Data were fit with a Hill equation (nRT, dotted line; APT, continuous line), yielding $r^{2}=0.98$ for $n R T$ and 0.96 for APT. Prob, Probability.

75-344 pA for APT, giving an upper limit for $\mathrm{CV}_{\mathrm{I}}(0.20 \pm 0.02$ for nRT, $0.20 \pm 0.04$ for APT; $p<0.05)$ and $\mathrm{CV}_{\mathrm{II}}(0.28 \pm 0.03$ for nRT and $0.21 \pm 0.04$ for APT; $p<0.05$ ) (Silver, 2003; Biró et al., 2006). Variance was highest for intermediate release probabilities and decreased for both high and low $\mathrm{Ca}^{2+} / \mathrm{Mg}^{2+}$ ratios in every cell (Fig. 7A3, B3). Weighted parabolic fits were applied to the variance-mean relationship (Silver, 2003) using both intrasite $\left(\mathrm{CV}_{\mathrm{I}}\right)$ and intersite $\left(\mathrm{CV}_{\mathrm{II}}\right)$ quantal variabilities (Fig. $\left.7 A 3, \mathrm{B3}\right)$ to a

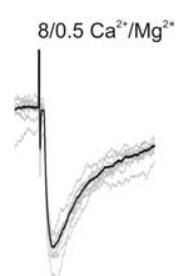

total of $9 \mathrm{nRT}$ and 12 APT cells fulfilling time-stable recording criteria for three different release probabilities. These fits yielded a number of release sites of $6.5 \pm$ 0.4 for nRT ( $n=9$; range $4-8$ ), whereas the value for APT was significantly greater, averaging $12.0 \pm 1.7(n=12$; range $3-27$; $p<0.05$ ) (Fig. 7C). The quantal sizes were similar $(18.9 \pm 1.9 \mathrm{pA}$ for $\mathrm{nRT}$ and $17.8 \pm$ $1.8 \mathrm{pA}$ for APT; $p>0.05$ ) and did not differ from the amplitude of successful monoquantal responses determined at low release probabilities and from the average mIPSC amplitudes $(p>0.05)$. Furthermore, release probabilities per release site, and their dependence on the $\mathrm{Ca}^{2+} / \mathrm{Mg}^{2+}$ ratio, were equal for $\mathrm{nRT}-\mathrm{Po}$ and APT-Po synapses (Fig. 7D) (half-maximal ratio of $1.99 \pm 0.63$ for $n R T$ and $2.35 \pm 1.06$ for APT). Therefore, consistent with the morphological analyses, APT synapses have a greater number of functionally independent release sites from which quantal events can be generated. However, our analysis disclosed multiple release sites in case of nRT fibers as well. Thus, both pathways are not only morphologically but also functionally multisynaptic. However, whereas APT terminals combine their active zones into a single terminal, nRT terminals keep them separate.

Computational methods were used to estimate the reliability of the multinomial fit across cells and for a single cell. We simulated vesicular release using binomial release statistics and Gaussian distributions of $q$ values defined by their mean and SD at low release probabilities (see Materials and Methods). Such simulations yielded $N$ and $q$ values that, on average, were very close to those determined experimentally (for nRT: $N=7.1 \pm 0.7$ and $q=20.6 \pm 1.3 \mathrm{pA}$, $p>0.05$ for both $N$ and $q$; for APT: $N=$ $11.6 \pm 2.8$ and $q=17.4 \pm 1.7 \mathrm{pA}, p>0.05$ for both $N$ and $q$ ). Typical examples between the fits to experimental and simulated data are presented in Figure 7, $A 3$ and $B 3$. The simulation and fitting were then repeated 100 times for the parameters of a single cell. The average values obtained were $100.6 \%$ and $105.1 \%$ of the experimental $N$ and $q$ values, with 41 and $49 \%$ of the trials deviating $<20 \%$ from these. Fewer than $15 \%$ of the trials reached values that deviated by $>50 \%$ from the mean.

\section{Characteristics of short-term plasticity for APT and nRT afferents}

In certain terminal types with a high number of active zones, a comparatively high stability of synaptic responses during multipulse stimulation has been observed (Kraushaar and Jonas, 2000; Telgkamp et al., 2004). Trains of 10 stimuli were applied to either 
nRT or APT at 10,50 , or $100 \mathrm{~Hz}$ to evoke repetitive IPSCs and to quantify their short-term plasticity $(n=5$ for $\mathrm{nRT}$; $n=$

3-5 for APT) (Fig. 8A). The stimulation frequency used here is within the range of in vivo discharge frequencies of $\mathrm{nRT}$ (Pinault, 2004) and APT neurons both in adult (Bokor et al., 2005) and in P18-d-old animals (supplemental Fig. S1, available at www.jneurosci.org as supplemental material). To assess the cumulative summation of IPSCs, the peak amplitude of each IPSC in the train, measured relative to the holding current preceding the train, was normalized to the first response (Fig. $8 \mathrm{B1}-$ B3). At $10 \mathrm{~Hz}$ stimulation, successive IPSCs showed an incremental depression that tended to be greater for nRT $(n=5)$ than for APT $(n=3)$ synapses (Fig. 8 Al, B1) $(p>0.05)$. At higher stimulation frequencies $(50-100 \mathrm{~Hz})$, however, the total current amplitude generated by 10 IPSCs was markedly greater for APT ( $n=5$ for both frequencies) than for $\mathrm{nRT}$ ( $n=5$ for both frequencies) and equalled or exceeded the amplitude of the first IPSC (Fig. $8 A 2, A 3, B 2, B 3)$.

Two additional analyses corroborated an enhanced stability of synaptic transmission during multipulse stimulation at APT synapses. First, we evaluated the amplitude of the persistent synaptic current that developed during successive IPSCs at 50$100 \mathrm{~Hz}$ stimulation for the same cells (Fig. 8A2,A3) (see Materials and Methods). Although both nRT and APT afferents produced such a current, markedly higher amplitudes were reached for APT-IPSCs (Fig. 8C1-C3). The persistent current component at $100 \mathrm{~Hz}$ stimulation amounted to $51.7 \pm 8.8 \%$ of the first amplitude of the nRT-IPSCs $(n=5)$, whereas it was $144.1 \pm 28.9 \%$ of the first current amplitude of the APT-IPSCs in the train $(n=5 ; p<0.05)$. Second, we calculated the charge transfer during multipulse stimulation by integrating the IPSC amplitudes over time (Fig. 8D) (see Materials and Methods). Charge transfer at APT synapses was $\sim 2$-fold greater after 10 pulses (Fig. 8D2) $(p<0.05$ for both 50 and $100 \mathrm{~Hz}$ ), or after an equal time integral (100 ms in Fig. 8D3) $(p<0.05$ for $50 \mathrm{~Hz}, p<$ 0.01 for $100 \mathrm{~Hz}$ ). This indicates that APT synapses produce greater synaptic inhibition during repeated firing for equivalent time periods.

Finally, we also analyzed tail currents obtained at the end of a $1 \mathrm{~s}$ stimulation train of nRT and APT afferents (supplemental Fig. S3, available at www.jneurosci.org as supplemental material). At all frequencies, nRT afferents gave rise to minor tail currents $<15$ pA that decayed with time constants $<20 \mathrm{~ms}(n=3-5)$ (supplemental Fig. S3, available at www.jneurosci.org as supplemental material). In contrast, APT stimulations resulted in pronounced,
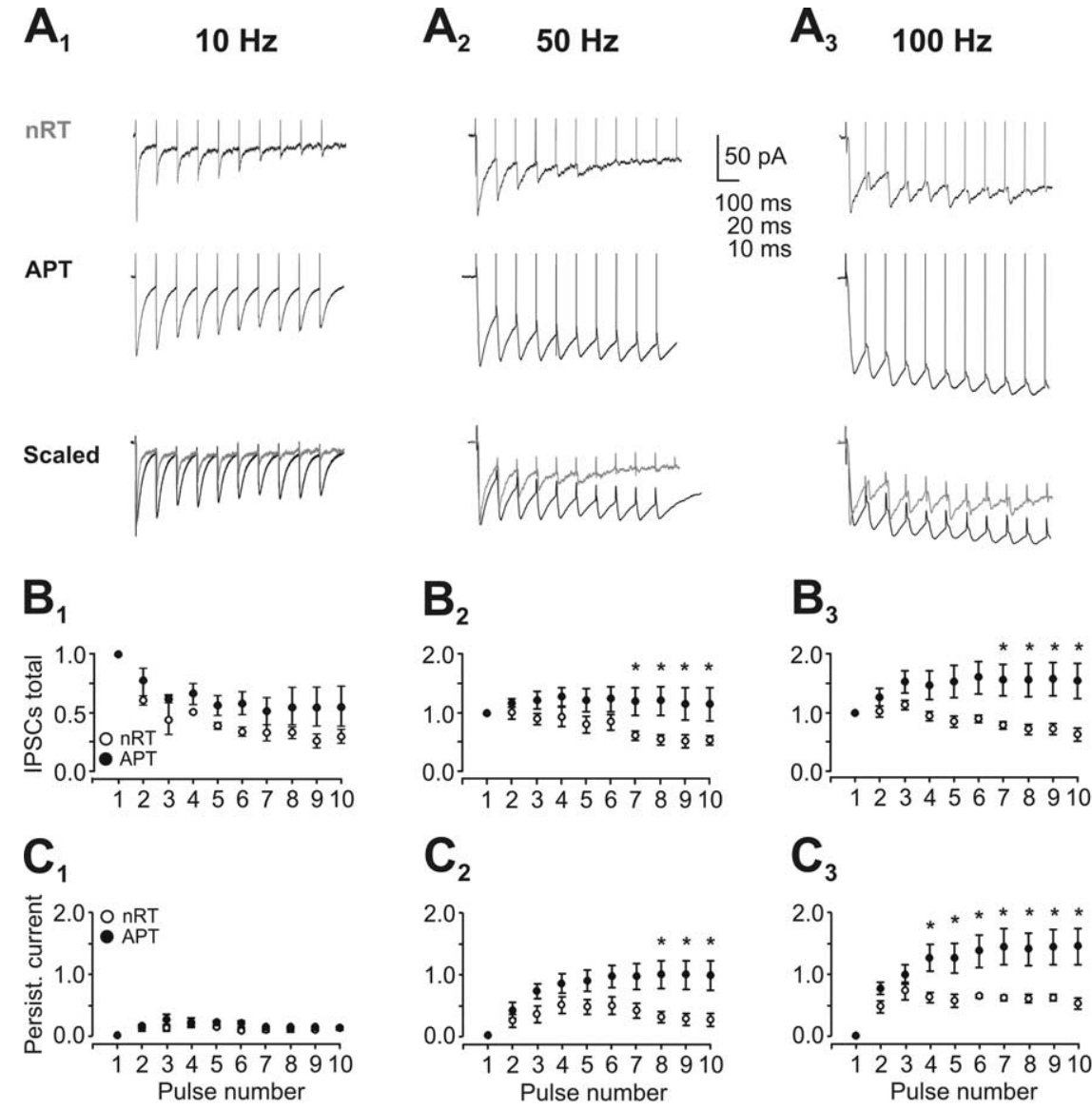

$\mathrm{C}_{2}$

$\mathrm{C}_{3}$
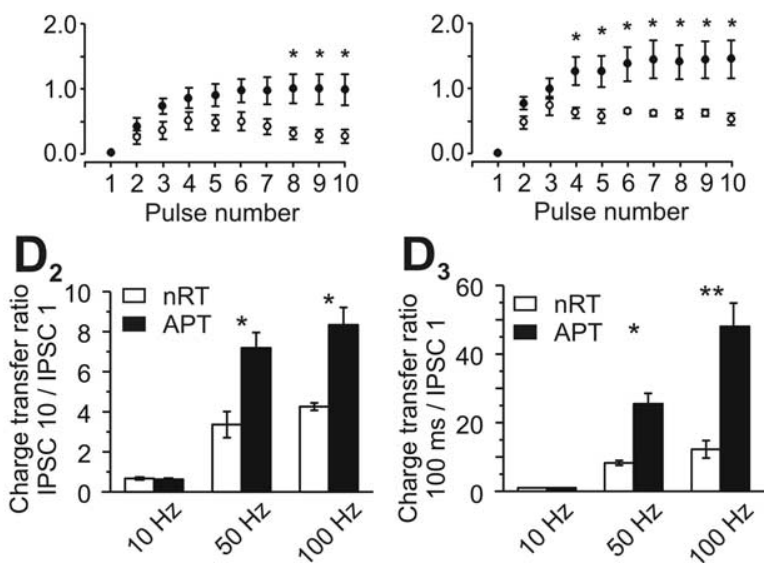

Figure 8. Short-term plasticity of $n R T$ - and APT-IPSCs during multipulse stimulation. A1-A3, Representative recordings of 10 successive IPSCs elicited at the frequencies indicated after stimulation of nRT (top) or APT terminals (middle). The nRT- (gray traces) and APT-IPSCs (black traces) were normalized to the first peak amplitude (scaled traces) and superimposed for a better $n=5$ ) or APT projections (black circles, $n=3$ for $10 \mathrm{~Hz}, n=5$ for 50 and $100 \mathrm{~Hz}$ ). C1-C3, Normalized persistent current amplitudes of 10 successive nRT- or APT-IPSCs. Note the greater current component developing in APT, as opposed to nRT-IPSCS. lation, performed for 10 stimuli or for $100 \mathrm{~ms}$ (see also Materials and Methods). D2, Ratio of charge transfer for 10 IPSCs, with respect to the first IPSC in the train. D3, Ratio of charge transfer after $100 \mathrm{~ms}$ of stimulation, with respect to the first IPSC. ${ }^{*} p<$ $0.05 ;{ }^{* *} p<0.01$. Persist, Persistent.

slowly decaying tails that assumed amplitudes up to $\sim 150 \mathrm{pA}$ (supplemental Fig. S3, available at www.jneurosci.org as supplemental material $)(p<0.05$ for $50 \mathrm{~Hz})$ and decayed with a slower time course $(\tau \sim 70-100 \mathrm{~ms}, p<0.05$ for 50 and $100 \mathrm{~Hz})$.

\section{Discussion}

In this study, we demonstrate that two independent inhibitory systems converging in the same thalamic nucleus display distinctively different synaptic ultrastructure and physiological properties. In both GABAergic pathways, single axons established multiple contacts on relay neurons with equal quantal sizes and release probabilities, yet the structural organization 
of active zones and synaptic short-term plasticity were radically different.

\section{Different organization of the $\mathrm{nRT}$ and APT-thalamic pathways}

Serial electron microscopic reconstruction demonstrated that all APT terminals innervate their postsynaptic partner via multiple synapses (on average, seven per terminal), whereas the vast majority of nRT boutons established a single synapse on each postsynaptic element. These morphological data are in agreement with previous observations of single electron microscopic sections (Montero and Scott, 1981; Cucchiaro et al., 1991; Liu et al., 1995b; Bokor et al., 2005). Quantal analysis of responses evoked by single fiber stimulation, however, clearly demonstrated multiple release sites in both pathways ( 6.5 and 12 in case of nRT and APT, respectively). The anatomical and physiological data sets are compatible only if we assume that a single nRT fiber contacts a relay cell via $6-7$ terminals with a single synapse each, whereas the 12 synapses of the APT input are formed by no more than one or two APT boutons. APT synapses of a single terminal are closely spaced to each other, within the hundred nanometer range, whereas individual nRT terminals converging on the same target innervate different parts of the dendritic tree (Cox et al., 1997), probably several micrometers away from each other.

Variance-mean analysis has been used successfully to correlate the number of morphologically observed active zones with the number of release sites at excitatory synapses (Silver, 2003; Biró et al., 2005). However, the only study on GABAergic terminals indicated a fivefold difference between the functionally determined release sites and the structurally identified active zones (Biró et al., 2006), indicative of multivesicular release. In our case, the " $N$ " of the APT input as determined by anatomy lies within the same range (2-16) as that defined by quantal analysis (3-27). Assuming that two large APT terminals can converge on the same target, consistent with observations at the light and electron microscopic levels, these results indicate that individual active zones of APT terminals release GABA in a predominantly uniquantal manner.

\section{Functional differences between the reticular and extrareticular pathways: spontaneous activity}

Po neurons received numerous high amplitude sIPSCs, which were absent from VB. Action potential-triggered GABA release from nRT terminals is of similar strength in different thalamic nuclei (Crabtree and Isaac, 2002; Lam and Sherman, 2007); therefore, nucleus-specific differences in release properties of nRT synapses are unlikely to account for the differences between VB and Po. Rather, the larger and slower spontaneous inhibitory events evident in Po neurons likely derive from the spontaneous discharge of APT inputs, which selectively innervate Po and are maintained in the horizontal slice (Bokor et al., 2005). With the exception of the largest Po events, the range of decay times of VB and Po sIPSCs was comparable, and both amplitudes and kinetic properties of the sIPSCs were within the range of those observed previously in VB of 3- to 4-week-old rats (Huntsman and Huguenard, 2000). Thus, although the anatomical data showed that nRT terminals innervate dendrites with larger diameter range than APT terminals, both types of IPSCs detected in this study appeared to be generated in an electrotonically equivalent cellular compartment, supposedly the thick proximal relay cell dendrites (Crunelli et al., 1987; Destexhe et al., 1998).

\section{Functional differences between the reticular and} extrareticular pathways: evoked responses

Evoked responses elicited in nRT consistently showed smaller size throughout a large range of release probabilities tested, reaching a maximum of $\sim 5$ quanta. The decay time constant of these evoked responses did not substantially differ from that of monoquantal responses. This suggests that $\mathrm{nRT}$ connections established by a single fiber are made up of a number of reliable synapses that release synchronously with little cross-talk among each other (Kraushaar and Jonas, 2000). Moreover, multiquantal release at nRT terminals appears to be highly synchronous, because decay time stays invariant against changes in release probability, similar to some hippocampal interneurons (Kraushaar and Jonas, 2000). Moreover, the high maximal release probability obtained $(>0.8)$ indicates faithful propagation of action potentials despite the complex axonal arborization of nRT axons (Pinault, 2004). The anatomical observation of a single synapse per target, or, in case of multisite nRT terminals, the orientation of synapses toward different targets and the glial barriers, support these physiological data and suggest that nRT-dependent inhibition relies on an efficiently timed point-to-point transmission at several independent release sites. This allows for the generation of short-lasting, precisely timed inhibitory events of adjacent relay cells.

In contrast to $\mathrm{nRT}$, the quantal content of evoked APT-IPSCs was greater $(\sim 10)$; response decay was slower and further decelerated with increased release probability. Such kinetic differences could reflect distinct gating kinetics of $\mathrm{GABA}_{\mathrm{A}}$ receptors located at APT synapses. However, there is no qualitative difference in synaptic $\mathrm{GABA}_{\mathrm{A}}$ receptor subunit distribution between Po and VB (Wisden et al., 1992; Fritschy and Mohler, 1995; Pirker et al., 2000; Peden et al., 2008); hence, this explanation is unlikely. Rather, our data support the interpretation that enhanced release leads to a prolonged presence of GABA in the synaptic cleft of APT synapses. A pooling of GABA has been described previously for terminals with multiple closely spaced active zones devoid of glial barriers that enable intersynaptic spillover (Telgkamp et al., 2004; Pugh and Raman, 2005).

\section{Functional differences between the reticular and extrareticular pathways: short-term plasticity}

Differences in synaptic ultrastructure and microenvironment strongly affect the short-term plasticity of IPSCs (Xu-Friedman and Regehr, 2004; Pugh and Raman, 2005), which is particularly important for reticular and extrareticular afferents, since both $\mathrm{nRT}$ and APT cells may fire in burst-discharge mode (Pinault, 2004; Bokor et al., 2005). Consistent with a previous qualitative investigation [see Cox et al. (1997), their Fig. 4B], we found that nRT synapses show depression of phasic responses at stimulation frequencies in the burst discharge range. However, we also found that $\mathrm{nRT}$ synapses failed to maintain inhibition, since persistent current components decayed within $<10$ stimuli. In contrast, APT synapses generated a much greater persistent current component at moderate and high stimulation frequencies that persisted for at least $1 \mathrm{~s}$ of continued stimulation. The decay time of tail currents evoked by prolonged stimulation trains was greater by almost an order of magnitude in case of APT terminals, pointing to an exceedingly prolonged presence of GABA. Cross talk among the multiple synapses of APT terminals is particularly amenable to generate such persistent current and to evoke not only phasic but maintained inhibition.

It should be noted that the differences in the number of synapses per target as well as the locations of nRT and APT terminals 
are analogous to the differences between the excitatory RS and RL profiles of the thalamus. The glutamatergic RS terminals contact distal dendrites via single active zones, whereas giant RL terminals of both cortical and subcortical origin target proximal dendrites via multiple active zones (for review, see Sherman and Guillery, 2006). Indeed, most unlabeled excitatory terminals next to nRT terminals were RS type; conversely, the majority of APT neighbors were RL type. Interestingly, however, the short-term plasticity of excitatory terminals is just the opposite of their GABAergic counterparts. Single site RS terminals display shortterm facilitation, whereas multisite RL terminals are characterized by pronounced short-term depression (Reichova and Sherman 2004; Groh et al., 2008). This suggests that during highfrequency input, the excitatory-inhibitory balance is differentially regulated in various dendritic compartments of relay cells. In distal dendrites, excitatory input prevails during high frequency activity, whereas at proximal regions inhibitory control remains strong.

\section{A novel GABAergic terminal type (F3) in the thalamus}

In cortical microcircuits, the classification of GABAergic interneuron populations is based on their postsynaptic target selection (Freund and Buzsáki, 1996). Our present data demonstrate that GABAergic inputs of the thalamus originating in distinct sources also display this type of heterogeneity. APT terminals selectively targeted proximal dendrites, whereas nRT targets all soma-dendritic domains in proportion of their occurrence. Analysis of the neighboring excitatory terminals suggested that APT terminals have selective control over the relay messages carried by large excitatory (driver) terminals, whereas $\mathrm{nRT}$ exerts a global effect over the entire dendritic tree.

Recently, several large GABAergic terminals of extrathalamic origin were characterized by similar ultrastructural features to APT boutons in various thalamic nuclei of the rat and monkey brain (Barthó et al., 2002; Bodor et al., 2008). GABAergic terminals of the thalamus have been classically subdivided into F1 or F2 terminals ( $\mathrm{F}$ referring to flattened vesicles) (Sherman and Guillery, 2006). Any axon terminals establishing symmetric synapses were regarded as F1 terminals, whereas the dendritic terminals of interneurons, which participate in serial synapses, were termed F2 terminals. Based on the substantially different morphological and physiological features, which apparently characterize several major GABAergic pathways of the thalamus, here we propose to define the "F3" terminal. The distinguishing features of F3 terminals are large size with multiple synapses converging on one target, a meshwork of $\mathrm{PA}$, complete glia sheet, preferential innervation of proximal dendrites, and enhanced stability of synaptic response during multipulse stimulation.

Previous studies demonstrated that GABAergic inhibition via F3 terminals is especially powerful. The incerto-thalamic pathway effectively blocks the relay of peripheral information transfer via feed forward inhibition (Trageser and Keller, 2004; Lavallée et al., 2005). Nigrothalamic input has a decisive role in synchronizing relay cells activity during spike-and-wave discharges (Paz et al., 2007) and may participate in establishing increased correlation between the activity of thalamic units in models of Parkinson's disease (Pessiglione et al., 2005). Previous work of the APTthalamic input demonstrated that activation of a single APT-thalamic fiber can lead to rebound burst discharge in the thalamus (Bokor et al., 2005). Our present data strongly suggest that the common mechanism behind these powerful effects on thalamocortical activity is based on the interaction among the multiple synapses of single extrathalamic F3 GABAergic terminals.

\section{References}

Auger C, Kondo S, Marty A (1998) Multivesicular release at single functional synaptic sites in cerebellar stellate and basket cells. J Neurosci 18:4532-4547.

Barthó P, Freund TF, Acsády L (2002) Selective GABAergic innervation of thalamic nuclei from zona incerta. Eur J Neurosci 16:999-1014.

Berod A, Hartman BK, Pujol JF (1981) Importance of fixation in immunohistochemistry: use of formaldehyde solutions at variable $\mathrm{pH}$ for the localization of tyrosine hydroxylase. J Histochem Cytochem 29:844-850.

Biró AA, Holderith NB, Nusser Z (2005) Quantal size is independent of the release probability at hippocampal excitatory synapses. J Neurosci 25:223-232.

Biró AA, Holderith NB, Nusser Z (2006) Release probability-dependent scaling of the postsynaptic responses at single hippocampal GABAergic synapses. J Neurosci 26:12487-12496.

Bodor AL, Giber K, Rovó Z, Ulbert I, Acsády L (2008) Structural correlates of efficient GABAergic transmission in the basal ganglia-thalamus pathway. J Neurosci 28:3090-3102.

Bokor H, Frère SG, Eyre MD, Slézia A, Ulbert I, Lüthi A, Acsády L (2005) Selective GABAergic control of higher-order thalamic relays. Neuron 45:929-940.

Buhl EH, Halasy K, Somogyi P (1994) Diverse sources of hippocampal unitary inhibitory postsynaptic potentials and the number of synaptic release sites. Nature 368:823-828.

Cox CL, Huguenard JR, Prince DA (1997) Nucleus reticularis neurons mediate diverse inhibitory effects in thalamus. Proc Natl Acad Sci U S A 94:8854-8859.

Crabtree JW, Isaac JT (2002) New intrathalamic pathways allowing modality-related and cross-modality switching in the dorsal thalamus. J Neurosci 22:8754-8761.

Crabtree JW, Collingridge GL, Isaac JT (1998) A new intrathalamic pathway linking modality-related nuclei in the dorsal thalamus. Nat Neurosci 1:389-394.

Crunelli V, Kelly JS, Leresche N, Pirchio M (1987) The ventral and dorsal lateral geniculate nucleus of the rat: intracellular recordings in vitro. J Physiol 384:587-601.

Cucchiaro JB, Uhlrich DJ, Sherman SM (1991) Electron-microscopic analysis of synaptic input from the perigeniculate nucleus to the A-laminae of the lateral geniculate nucleus in cats. J Comp Neurol 310:316-336.

Destexhe A, Neubig M, Ulrich D, Huguenard J (1998) Dendritic lowthreshold calcium currents in thalamic relay cells. J Neurosci 18:3574-3588.

Freund TF, Buzsáki G (1996) Interneurons of the hippocampus. Hippocampus 6:347-470.

Fritschy JM, Mohler H (1995) GABAA-receptor heterogeneity in the adult rat brain: differential regional and cellular distribution of seven major subunits. J Comp Neurol 359:154-194.

Giber K, Slézia A, Bokor H, Bodor AL, Ludányi A, Katona I, Acsády L (2008) Heterogeneous output pathways link the anterior pretectal nucleus with the zona incerta and the thalamus in rat. J Comp Neurol 506:122-140.

Groh A, de Kock C, Wimmer V, Sakmann B, Kuner T (2008) Driver or coincidence detector: modal switch of a corticothalamic giant synapse controlled by spontaneous activity and short-term depression. J Neurosci 28:9652-9663.

Guillery RW, Sherman SM (2002) Thalamic relay functions and their role in corticocortical communication: generalizations from the visual system. Neuron 33:163-175.

Gulyás AI, Miles R, Sík A, Tóth K, Tamamaki N, Freund TF (1993) Hippocampal pyramidal cells excite inhibitory neurons through a single release site. Nature 366:683-687.

Hodgson AJ, Penke B, Erdei A, Chubb IW, Somogyi P (1985) Antisera to gamma-aminobutyric acid. I. Production and characterization using a new model system. J Histochem Cytochem 33:229-239.

Huntsman MM, Huguenard JR (2000) Nucleus-specific differences in GABA(A)-receptor-mediated inhibition are enhanced during thalamic development. J Neurophysiol 83:350-358.

Kraushaar U, Jonas P (2000) Efficacy and stability of quantal GABA release at a hippocampal interneuron-principal neuron synapse. J Neurosci 20:5594-5607. 
Lam YW, Sherman SM (2007) Different topography of the reticulothalmic inputs to first- and higher-order somatosensory thalamic relays revealed using photostimulation. J Neurophys 98:2903-2909.

Lavallée P, Urbain N, Dufresne C, Bokor H, Acsády L, Deschênes M (2005) Feedforward inhibitory control of sensory information in higher-order thalamic nuclei. J Neurosci 25:7489-7498.

Lieberman AR, Spacek J (1997) Filamentous contacts: the ultrastructure and three-dimensional organization of specialized non-synaptic interneuronal appositions in thalamic relay nuclei. Cell Tissue Res 288:43-57.

Liu XB, Honda CN, Jones EG (1995a) Distribution of four types of synapse on physiologically identified relay neurons in the ventral posterior thalamic nucleus of the cat. J Comp Neurol 352:69-91.

Liu XB, Warren RA, Jones EG (1995b) Synaptic distribution of afferents from reticular nucleus in ventroposterior nucleus of cat thalamus. J Comp Neurol 352:187-202.

Montero VM (1983) Ultrastructural identification of axon terminals from the thalamic reticular nucleus in the medial geniculate nucleus in the rat: an EM autoradiographic study. Exp Brain Res 51:338-342.

Montero VM, Scott GL (1981) Synaptic terminals in the dorsal lateral geniculate nucleus from neurons of the thalamic reticular nucleus: a light and electron microscope autoradiographic study. Neuroscience 6:2561-2577.

Paxinos G, Watson C (1998) The rat brain in stereotaxic coordinates, Ed 4. London: Academic.

Paz JT, Chavez M, Saillet S, Deniau JM, Charpier S (2007) Activity of ventral medial thalamic neurons during absence seizures and modulation of cortical paroxysms by the nigrothalamic pathway. J Neurosci 27:929-941.

Peden DR, Petitjean CM, Herd MB, Durakoglugil MS, Rosahl TW, Wafford K, Homanics GE, Belelli D, Fritschy JM, Lambert JJ (2008) Developmental maturation of synaptic and extrasynaptic GABAA receptors in mouse thalamic ventrobasal neurones. J Physiol 586:965-987.

Pessiglione M, Guehl D, Rolland AS, François C, Hirsch EC, Féger J, Tremblay L (2005) Thalamic neuronal activity in dopamine-depleted primates: evidence for a loss of functional segregation within basal ganglia circuits. J Neurosci 25:1523-1531.

Pinault D (2004) The thalamic reticular nucleus: structure, function and concept. Brain Res Brain Res Rev 46:1-31.

Pinault D, Deschênes M (1998) Projection and innervation patterns of individual thalamic reticular axons in the thalamus of the adult rat: a threedimensional, graphic, and morphometric analysis. J Comp Neurol 391:180-203.

Pinault D, Bourassa J, Deschênes M (1995) The axonal arborization of sin- gle thalamic reticular neurons in the somatosensory thalamus of the rat. Eur J Neurosci 7:31-40.

Pirker S, Schwarzer C, Wieselthaler A, Sieghart W, Sperk G (2000) GABA(A) receptors: immunocytochemical distribution of 13 subunits in the adult rat brain. Neuroscience 101:815-850.

Pugh JR, Raman IM (2005) GABAA receptor kinetics in the cerebellar nuclei: evidence for detection of transmitter from distant release sites. Biophys J 88:1740-1754.

Reichova I, Sherman SM (2004) Somatosensory corticothalamic projections: distinguishing drivers from modulators. J Neurophysiol 92:2185-2197.

Saviane C, Silver RA (2006) Fast vesicle reloading and a large pool sustain high bandwidth transmission at a central synapse. Nature 439:983-987.

Schneggenburger R, Meyer AC, Neher E (1999) Released fraction and total size of a pool of immediately available transmitter quanta at a calyx synapse. Neuron 23:399-409.

Shepherd GM, Harris KM (1998) Three-dimensional structure and composition of CA3 $\rightarrow$ CA1 axons in rat hippocampal slices: implications for presynaptic connectivity and compartmentalization. J Neurosci 18:8300-8310.

Sherman S, Guillery R (2006) Exploring the thalamus and its role in cortical function. Cambridge, MA: MIT.

Silver RA (2003) Estimation of nonuniform quantal parameters with multiple-probability fluctuation analysis: theory, application and limitations. J Neurosci Methods 130:127-141.

Somogyi P, Hodgson AJ, Chubb IW, Penke B, Erdei A (1985) Antisera to gamma-aminobutyric acid. II. Immunocytochemical application to the central nervous system. J Histochem Cytochem 33:240-248.

Tamás G, Somogyi P, Buhl EH (1998) Differentially interconnected networks of GABAergic interneurons in the visual cortex of the cat. J Neurosci 18:4255-4270.

Telgkamp P, Padgett DE, Ledoux VA, Woolley CS, Raman IM (2004) Maintenance of high-frequency transmission at purkinje to cerebellar nuclear synapses by spillover from boutons with multiple release sites. Neuron 41:113-126.

Trageser JC, Keller A (2004) Reducing the uncertainty: gating of peripheral inputs by zona incerta. J Neurosci 24:8911-8915.

Wisden W, Laurie DJ, Monyer H, Seeburg PH (1992) The distribution of 13 GABAA receptor subunit mRNAs in the rat brain. I. Telencephalon, diencephalon, mesencephalon. J Neurosci 12:1040-1062.

Xu-Friedman MA, Regehr WG (2004) Structural contributions to shortterm synaptic plasticity. Physiol Rev 84:69-85. 